\title{
Social cooperation in the context of integrated private and common land management
}

\author{
Habtamu Tilahun Kassahun ${ }^{1, \dagger}$, Bo Jellesmark Thorsen ${ }^{2}$, Joffre Swait ${ }^{3}$, \\ Jette Bredahl Jacobsen ${ }^{2}$ \\ ${ }^{1}$ Australian Rivers Institute, Griffith University, Nathan, Australia \\ ${ }^{2}$ Department of Food and Resource Economics and Centre for Macroecology, evolution and \\ climate, University of Copenhagen, Denmark \\ ${ }^{3}$ School of Health Policy \& Management and Erasmus Choice Modelling Centre, Erasmus \\ University Rotterdam, Netherlands
}

${ }^{\dagger}$ Corresponding author: $\underline{\text { h.kassahun@griffith.edu.au }}$

\section{Citation}

Kassahun, H.T., Thorsen, B.J., Swait, J., Jacobsen, J.B., 2020. Social Cooperation in the Context of Integrated Private and Common Land Management. Environ. Resource Econ. $75,105-136$.

\begin{abstract}
Several discrete choice experiment studies have investigated issues in the design of incentive programs to enhance the provision of ecosystem services. In these studies, ownership of land is usually private, and landowners make decisions independently of each other. However, the assumption of independence may be invalid when decision making involves a spatial setting and social networks. This study presents a new approach that accounts for social cooperation and preference interdependence across farmers in a land management context with mixed ownership. We formulate an econometric model of implicit choice set formation that accounts for (1) farmers' expectations regarding mutual positive benefits from cooperation in an integrated land management system, and (2) the potential interdependence of preferences across farmers within the same socio-spatial group. We show that cooperation expectations matter for the decision of whether to engage in cooperative management and also for welfare estimates. Our model can identify sources of heterogeneities arising from cooperation expectations in ways that would not be possible using a reduced-form choice model. The assumption of independence should be checked routinely in similar settings to avoid potential endogeneity problems in discrete choice models when dealing with data that have a socialspatial dimension.
\end{abstract}

Keywords: Choice set formation; Common pool; Ethiopia; Hybrid choice; Land management; Latent variable; Social interaction; Social network;

JEL classification: D70; Q15; Q24; Q5 


\section{Introduction}

In recent years, several discrete choice experiments (DCEs) studies have investigated issues in the design of incentive programs to encourage land owners to enhance the provision of ecosystem services from their land (Broch and Vedel 2012, Broch et al. 2013, Christensen et al. 2011, Tesfaye and Brouwer 2012, Kaczan et al. 2013, Krishna et al. 2013, Greiner et al. 2014, Lienhoop and Brouwer 2015, Vedel et al. 2015, Banerjee 2017). These studies and experiments all assume that land owners have exclusive property rights over their land. Thus, land owners are either asked to voluntarily adopt a specified type of land management technology or to give up some of their property rights in return for different forms of incentives - typically conditional payments.

Even in countries where common property ownership of land exists and where ecosystem service provision may depend in part on these lands, researchers often exclusively focus on the segment of land owned or controlled by private agents in their studies of the provision of ecosystem services (e.g., Tesfaye and Brouwer (2012)). This may be because the scenario of private ownership has the best fit to the investigated policy instrument and to economic theory. However, in mixed land ownership systems (with both private and common land), ignoring the proportion of land under common ownership may reduce the relevance of policy designs (Pelosi et al. 2010, Ostrom and Cox 2010, Epanchin-Niell and Wilen 2015).

Management of common lands requires cooperation, and land owners are likely to take into account their beliefs about expected benefits of cooperation when making decisions. Several studies have documented the importance of conditional cooperation behavior, e.g., the tendency of individuals to cooperate if they believe that other individuals will cooperate or the creation of incentives to minimize socially unacceptable behavior, using laboratory experiments and field studies (Rustagi et al. 2010, Ostrom 1990, Ostrom et al. 1999, Vollan 
and Ostrom 2010, Richards et al. 2014, Cavalcanti et al. 2013). Strong cooperation patterns and mutual trust among land owners are observed in social networks (Karlan et al. 2009, Videras et al. 2012, Cavalcanti et al. 2013, Neilson and Wichmann 2014). Consequently, land owners can engage in the management of the common land with others when cooperation leads to positive outcomes. However, if farmers' expectations with respect to cooperation outcomes are negative, they may decline to participate in a cooperative land management agreement. DCE studies of land owners' decision making in such settings need to account for the role that expectations regarding cooperation outcomes may have in defining what decision alternatives land owners consider relevant/feasible alternatives (i.e., choice set formation). This is important because misspecification of choice sets will lead to misleading conclusions about model parameters and, therefore, welfare estimates (Li et al. 2015, Swait and Ben-Akiva 1987, Thiene et al. 2017).

In this study we investigate the effectiveness and welfare impacts of incentives for farmers in the Ethiopian highlands to undertake measures on private and/or common lands to reduce onfarm and off-farm impacts of soil erosion threatening the Blue Nile river system. To handle the common lands decision aspect, we develop an econometric model of implicit choice set formation that accounts for land owners' expectations regarding cooperation outcomes, and further account for the potential interdependence of preferences across land owners. In many survey data analyses, it is almost universally assumed that data and choices of randomly selected individuals in the population of interest are independent across individuals. The assumption of independence is very helpful for econometric model development and makes estimation less fraught. However, in a case like ours, the choices of individuals may not be independent for a number of reasons, including unobserved spatial and social network effects (Sidharthan and Bhat 2012, Brady and Irwin 2011, Walker et al. 2011, Klaiber and Phaneuf 2010, Bhat 2000, Tobler 1979, McFadden 2010, Ben-Akiva et al. 2012, Manski 1993a, Manski 
1993b). Thus, unobserved contextual factors may influence the preferences (hence decisions) of any individual and be correlated with the decisions of other individuals in the same social and spatial proximity ${ }^{1}$, creating an endogeneity issue. To avoid such potential endogeneity in preferences, we introduce unobserved heterogeneity between spatial and/or social groups' expectations with regard to the mutual benefits of cooperation and use that as an instrument in a hybrid choice model.

We demonstrate the importance for modeling and for policy analysis of accounting for interdependence of choices across individuals in a context where social-spatial interactions affect individuals in unobserved ways. Thus, our study contributes to the literature discussing the importance of accounting for spatial or social interaction among decision makers for accurate predictions of outcomes in discrete choice settings (Ben-Akiva et al. 2012, McFadden 2010, Manski 1993a, Manski 1993b, Richards et al. 2014, Brock and Durlauf 2001).

The article is organized as follows. First, we present the case study, providing context for the development of our theoretical model framework, which we develop in sequence. This includes the econometric model specification and model identification issues. Third, we report and discuss empirical findings. Finally, we summarize findings and make recommendations for practice.

\section{Case study}

The case study region is situated in the Ethiopian highlands of the Upper Blue Nile Basin. Soil erosion threatens the livelihoods of millions of farmers in the Ethiopian highlands and damages the water infrastructure across the Blue Nile River System (Awulachew et al., 2008; Steenhuis et al., 2009). However, farmers' voluntary adoption rate of soil conservation technologies is

\footnotetext{
${ }^{1}$ Social-spatial proximity is represented as a local area within which individuals belong to a social network, and live and work in the same local area. Therefore, individuals share common landscape characteristics and social network.
} 
very low for a number of reasons, e.g., poor incentive mechanisms for soil conservation, absence or inadequacy of credit facilities enabling investment in conservation infrastructures with high initial investment cost, and lack of adequate agricultural extension services providing management support (see Tesfaye and Brouwer, 2012). Moreover, policy and research directions mainly focus on the management of private land and ignore the proportion of land under common pool governance (Awulachew et al., 2008, Kassahun and Jacobsen, 2015).

Thus, our DCE data collection instrument was designed to address measures and incentives for undertaking both private and common land management initiatives to reduce on-farm and offfarm impacts of soil erosion. The resulting dataset was reported in a related study by Kassahun and Jacobsen (2015), who analyzed the choice data using a structured latent class approach ${ }^{2}$. However, their analysis did not address the potential screening processes of alternatives as well as potential endogeneity issues arising due to interdependence of choices across the responding farmers sharing both spatial and social networks.

\subsection{Survey and sampling design}

The survey and sampling design accounts for both spatial and social heterogeneity. The Choke Mountain region is considered both an erosion hotspot (Awulachew et al. 2008) and the water tower of the Blue Nile Basin (Teferi et al. 2010). Four of the most active erosion hot-spot subwatersheds (sub-districts) in the Choke Mountain systems were selected for inclusion in this study (Figure 1).

\footnotetext{
${ }^{2}$ See Kassahun and Jacobsen (2015) model specification in Appendix A.
} 

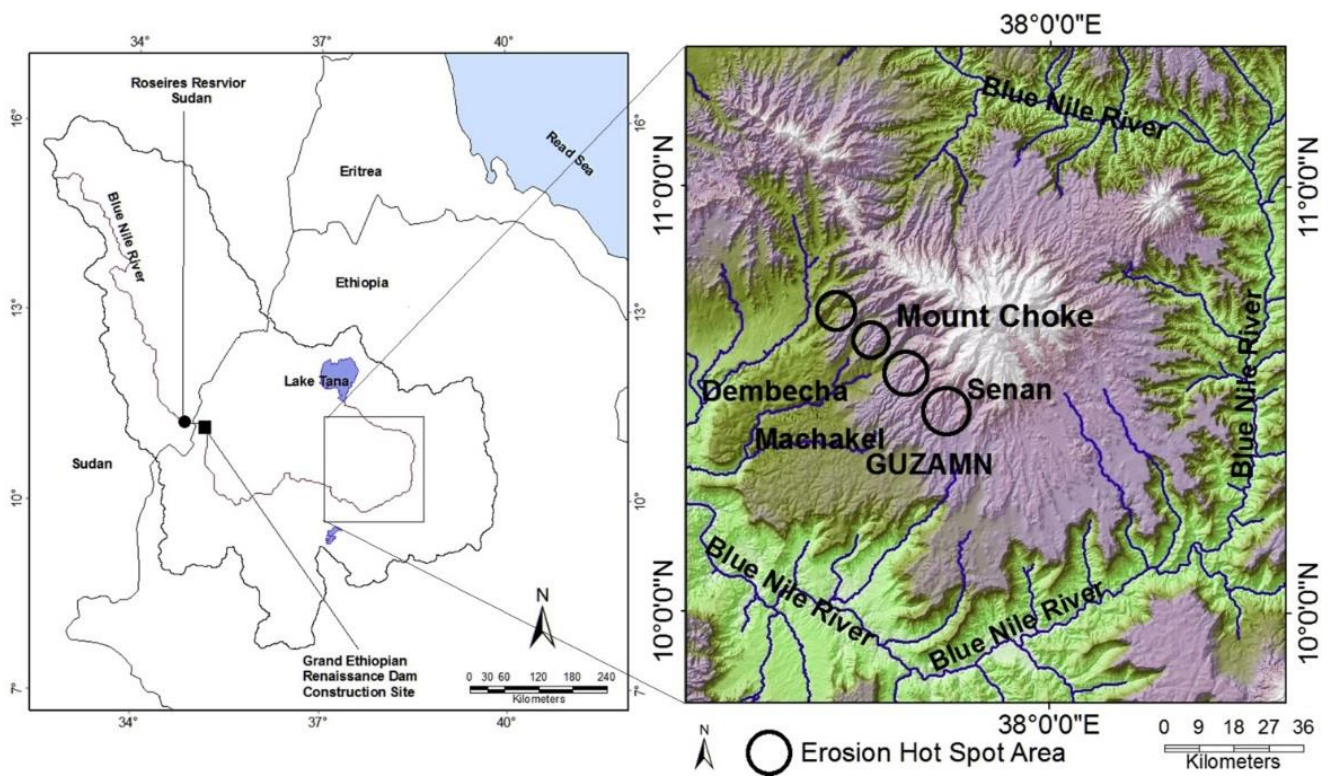

Figure 1. Blue Nile Basin and erosion hot spot area (source: Kassahun and Jacobsen (2015)).

The four sub-watersheds were identified from Denbecha (Gelila1 and Gelila2), Machakel and Senan districts, from which 90 farmer development groups (FDGs) were randomly selected. The FDGs were established in 2008 by the regional government based on spatial proximity. For details on how the FDGs were established and function in the government and political system see Emmenegger et al. (2011). The selected FDGs accounted for half of the total FDGs in the area. Every farmer is a member of only one FDG, and she or he represents their household (i.e., one farmer per household). After the FDGs were identified, four or five individuals were randomly selected from different households in each FDG based on membership size (which ranged from 20 to 30 households per FDG). In total, 400 individuals were interviewed for the study.

The main reason for employing stratified sampling was that prior to the study we did not know the degree of preference homogeneity within a given area (i.e., the social-spatial proximity). If there was evidence for high preference homogeneity within a given social-spatial proximity, 
the sample size from a FDG could be reduced and instead the geographical coverage of the sample could be expanded (Kassahun and Jacobsen 2015).

\subsection{Designing the DCE}

An important point in designing a DCE in a developing country context is how to fully engage with respondents and secure their attention while defining and explaining attributes and attribute levels. If there are misunderstandings or respondents experience fatigue, the reliability of the study is questionable. A successful application of DCEs requires a substantial effort from development to implementation of survey instruments (Bennett and Birol 2010, Kassahun 2014). For example, the book chapters in Bennett and Birol (2010) showed successful application of DCEs for a wide range of goods and services across developing countries and provided working guidelines drawn from field experiences. Most importantly, focus group discussion and pre-testing before the actual survey implementation is critical. Many of the potential issues of SP methods can be minimized before and during the process of data collection, following these guidelines.

During the first survey pre-test we noticed that respondents lost interest when attributes and attribute levels were explained to them. In the second pre-test, to adjust for this behavior, we asked a general question related to the attribute of interest and let respondents first explain their thoughts about the attribute. Thus engaged, we then provided a detailed explanation of the attributes of the DCE supported with pictures. This approach worked very well. The pre-tests and the final DCE survey were administered face to face by well-trained and experienced enumerators in household interview techniques in rural (Kassahun 2014). During the interview period most of the enumerators were employed by the Regional Central Statistical Agency of Ethiopia (CSA). We believe the face-to-face technique may reduce possible fatigue problems, compared to filling out surveys on your own. 
Once we had identified prior information about attributes, attribute labels and parameters from our two pre-tests, focus group discussions and literature, we sought a fractional factorial design optimized for D-efficiency of a multinomial logit model for use in the survey. Accordingly, we generated 36 choice tasks and separated them into 4 blocks, each farmer receiving 9 choice tasks, each of which contained two policy alternatives and one status quo option ${ }^{3}$. We presented a single choice task at a time and instructed farmers to disregard prior tasks when they responded to a given choice task. About $75 \%$ of the interviews were conducted on the farms during the annual conservation program campaign of the government from mid-January to March 2013.

Each choice alternative was described by eight attributes, including three attributes related to the choice of on-farm soil conservation structures on private land: Soil Bund with grass strip, Fanya Juu ${ }^{4}$ with grass strip, and Stone Bund (Table 1). The effectiveness of these on-farm conservation structures differs by topography. Depending on the topography on the farm, farmers may prefer one or more of the on-farm soil conservation measures. The DCE design allows for all possible combinations of on-farm soil conservation measures as well as the "none-of-them" options to appear in any given policy alternative. Thus, the three on-farm conservation attributes and the none-option are treated independently in the DCE design (see Table 1). However, in the choice card, they were categorized under the name of "on-farm conservation" (Figure 2). Categorization is one of the strategies reducing choice complexity in a decision process (Swait and Adamowicz 2014, Swait et al. 2014).

\footnotetext{
${ }^{3}$ The status quo alternative represents the actual practices (dominant practices) for each attribute in the watershed during the study period.

${ }^{4}$ Fanya Juu is a middle intensity conservation structure practiced in the area. Terraces are made by digging ditches and trenches along the contour and throwing the soil uphill to form an embankment.
} 
Table 1. Attributes and attribute levels used in the choice experiment copied from Kassahun and Jacobsen (2015).

\begin{tabular}{|c|c|c|}
\hline Attributes & Attribute Levels & Status quo \\
\hline Soil bund with grass strip $=1$ & 0,1 & 0 \\
\hline Fanya Juu with grass strip $=1$ & 0,1 & 0 \\
\hline Stone bund $=1$ & 0,1 & 0 \\
\hline \multirow{2}{*}{ Livestock production system } & Free grazing $=0$ & 0 \\
\hline & $\begin{array}{l}\text { Cut and carry option with semi- } \\
\text { privatization }=1\end{array}$ & \\
\hline Labor contribution & $12,24,36,48,60,72$ (days/year) & 48 \\
\hline \multirow{3}{*}{ Timing of labor contribution } & One time continuous $=0$ & 0 \\
\hline & Equally distributed between the 12 & \\
\hline & Months $=1$ & \\
\hline Additional Extension service & $0,2,4,6,8,12$ (days/year) & 0 \\
\hline \multicolumn{3}{|l|}{ Loan subsidy per year } \\
\hline Monetary compensation from & $0 / 0 / 0$ & $0 / 0 / 0$ \\
\hline credit Facility for implementing & 1200/25/77, & \\
\hline appropriate & $2400 / 50 / 154$ & \\
\hline management strategies: & $3600 / 75 / 232$ & \\
\hline$(\mathrm{x} / \mathrm{y} / \mathrm{z})^{*}$ & $4800 / 100 / 309$ & \\
\hline & $6000 / 125 / 386$ & \\
\hline
\end{tabular}

$(\bar{x} / y / z) *-x$ Ethiopian birr (ETB) interest free loan paid back by y birr per month over the period of 4 years corresponding to a present value of $\mathrm{z}$ ETB/year monetary compensation. $\mathrm{z}$ is the level shown in the model estimates. The current commercial Bank of Ethiopia interest rate for agricultural funds, $9.5 \%$, is used for the conversion. 


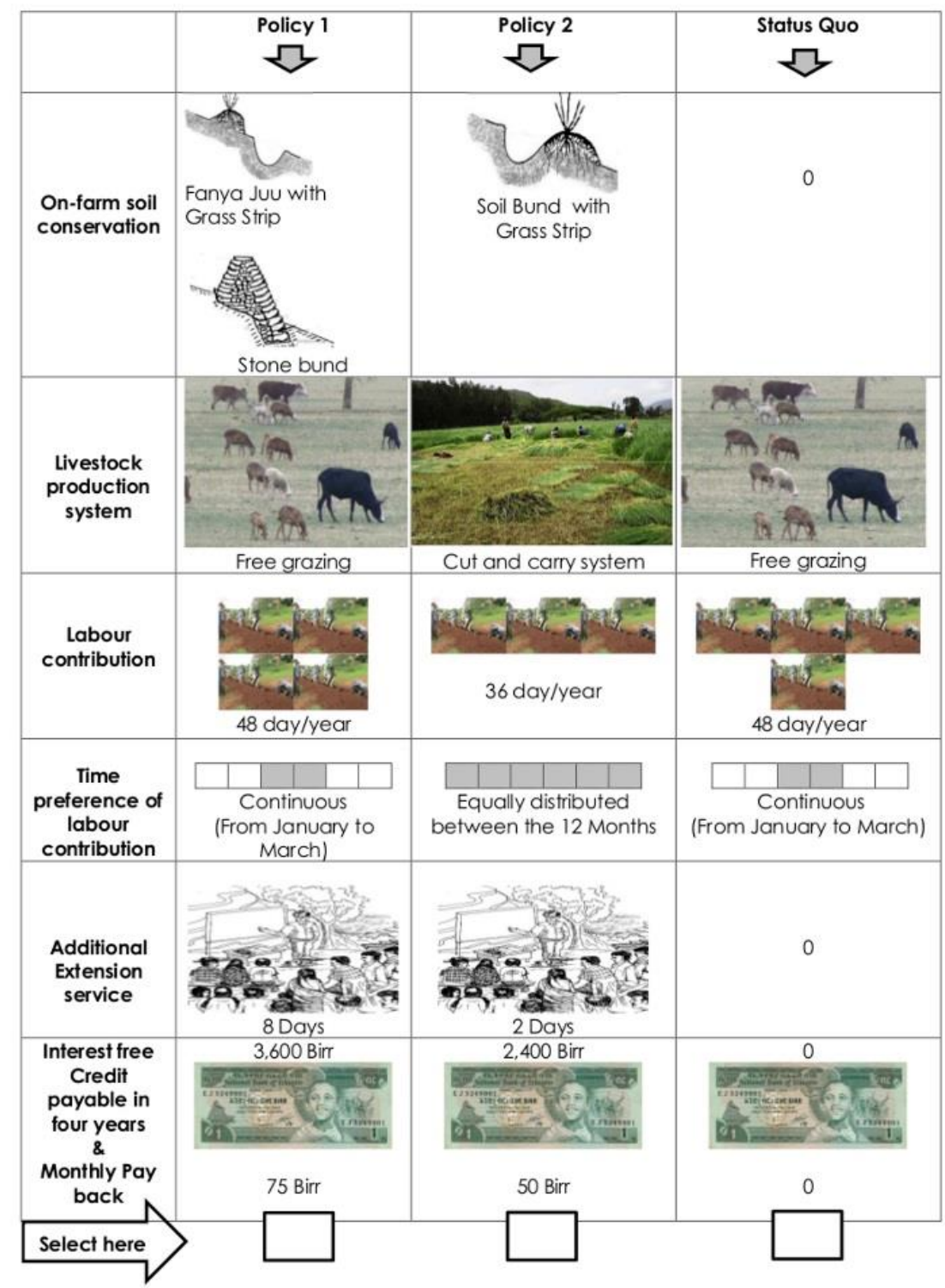

Figure 2. Example of choice card copied from Kassahun and Jacobsen (2015). A fractional factorial design is used to generate 36 choice cards. The design is optimized for D-efficiency using priors obtained from our pilot study for a multinomial logit model. Each respondent saw nine choice cards.

The fourth attribute, of particular interest here, was livestock production systems on common land. Free grazing contributes about $66 \%$ of the soil erosion in the Upper Blue Nile Basin (Awulachew et al. 2008). Thus, any meaningful reduction in soil erosion should target a reduction of the amount of land under free grazing. Accordingly, the livestock production system on common land could take two levels in our design, "free grazing" or "cut and carry". A mix of common and private land use governance systems has been found to constitute an effective resource management system in some cases (Trawick 2001, Ostrom and Cox 2010, 
Ostrom 1990, Cox and Ross 2011). However, a mixed land management system requires shared ownership and rules that bind each resource user's access to and use of the common pool resources (Ostrom et al. 1999). Thus, the "cut and carry" livestock management option was presented under the following description:

"In this system, animal movement is restricted. The available communal grazing land is divided equally and each plot of land is given to 5 households, who organize themselves according to their own interests, for communal management and the development of livestock feed. Communal grazing lands will be managed together to produce high quality animal feed. Technical expert support will be provided by the district agricultural office. ${ }^{, 5}$

The number of farmers for managing the "cut and carry" system was determined based on the information from our focus group discussions. In the four sub-watersheds, between 4.4 and 8.2 ha of grazing land per five households was available (Kassahun and Jacobsen 2015). Nevertheless, we did not inform respondents how much land would be available to them under the cut and carry livestock management system, because of the difficulty of obtaining accurate

\footnotetext{
${ }^{5}$ We adjusted the definition of the cut and carry livestock management option in the second pre-test following the discovery of concerns over free-rider and trust issues in our focus group discussion and first pre-test of the survey. In the first pre-test cut and carry livestock management option was defined as:

"In cut and carry livestock management system, animal movement is restricted. Communal grazing lands will be managed together to produce high-quality animal feed. Technical expert support will be provided by the district agricultural office."

The first pre-test led to strong rejection of the alternatives that contained the attributes of cut and carry livestock management system. The overly generic description of the mechanism caused focus groups members and pretest respondent to raise concerns that the unspecified group size and mechanism behind 'managed together' could imply options for free-riding and did not inspire trust.
} 
figures for each spatial unit. Thus, they formed their own ideas on this aspect. This contributes to unobserved heterogeneity to be captured in the modeling approach using individual specific constants.

The fifth and sixth attributes were related to the households' labor contributions towards the watershed management works, specifically the number of days and the timing of those days. Currently, every year from January to March inclusive (but excluding weekends and religious holidays), farmers are required to contribute 48 days of labor to that end. Our experiment was designed to elicit willingness to contribute more or less than currently required, under the selected possible new management alternatives, as well as the preferred timing of this labor contribution. In the focus group discussion, farmers showed a dislike for the possibility of providing further labor contributions beyond the agricultural harvest season.

Implementing specific watershed management activities requires knowledge, and therefore, an additional extension service was included to address this issue as the seventh attribute. Currently, there are different types of agricultural extension services offered to farmers. However, the current extension services are not targeted enough to be able to support the implementation of the planned watershed management activities in this study (for example, there is no cut and carry livestock management system extension service).

Finally, in the eighth attribute farmers were informed that to facilitate the implementation process of the watershed management plan a subsidized credit facility would be available for them up to a maximum of 6,000 birr at zero interest rate. The money would be gradually paid back at the end of each month over 4 years. Farmers were informed that "the contract will be renewed every 4 years upon satisfactory implementation of the integrated watershed management plan. The Keble (sub-district) agricultural development agent and Keble administration monitor the implementation of the plan". On the choice card, respondents saw 
the amount of credit and the pay back amount per month (Figure 2). In this study, the present value of the monetary compensation (subsidy) is calculated using a 9.5\% loan (corresponding to the interest rate of the commercial Bank of Ethiopia). We then use the present value to estimate models and calculate the willingness to accept (WTA) value of different measures.

Note that using credit and labor as payment vehicles simultaneously is not a new idea, including using them in combination. The access to credit is one of the most limiting factors for adoption of conservation technologies in developing countries. Previously Tesfaye and Brouwer (2012) used credit as a payment vehicle to incentivize the adoption of soil conservation. They considered land productivity gain as a reward to farmers. In our study, in addition to the direct benefits to farmers of land productivity gains, farmers also provide ecosystem services for downstream users. The cost of credit is fully subsidized in the DCE design, reflecting a WTA measure. In return, farmers may agree to provide additional labor to implement different types of watershed management activities, which reflects a willingness to pay (WTP) for the change. It is also possible to reduce the labor offer from the current requirement, reflecting a willingness to accept (WTA) interpretation. Note that from the farmers' perspective, if the benefit of implementing any type of watershed management activity is high, we expect farmers to require less subsidy to implement the watershed management activities. However, care must be taken whenever non-monetary payments vehicles are used to elicit value ${ }^{6}$.

\subsection{Expected cooperation measurement indicator}

Following the DCE portion our survey includes various follow-up items including questions related to expectations about common land cooperation, socioeconomics and spatial aspects. To obtain a measure of expectations regarding cooperation outcomes under the "cut and carry" livestock management system, respondents are asked to state their agreement/disagreement on

\footnotetext{
${ }^{6}$ See details in the caveat section of using non-monetary payment vehicles.
} 
the following statement: "We can benefit more from livestock production when we avoid free grazing and substitute with group participatory grass (forage) development and management”. Figure 3 displays the distribution of respondents' responses ${ }^{7}$.

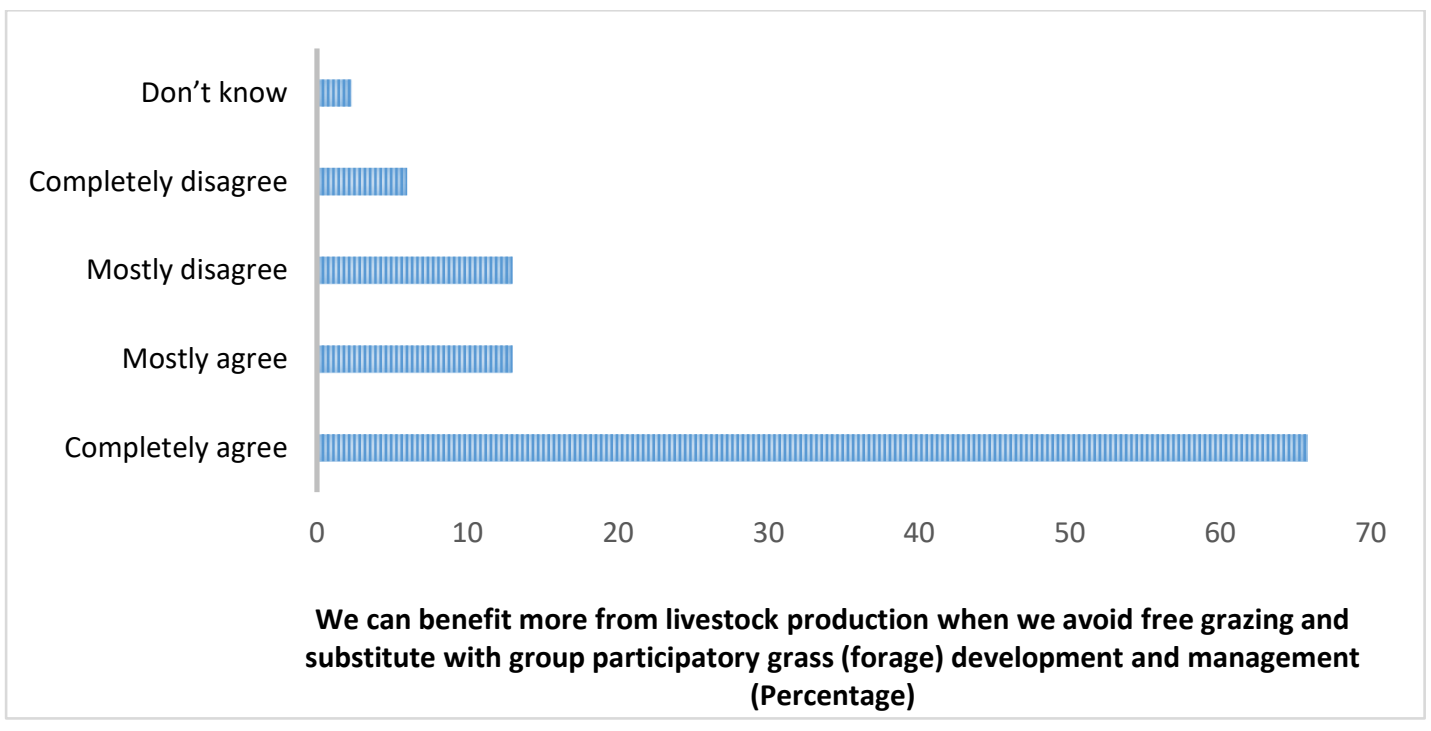

Figure 3. Attitudinal questions for the benefit of cut and carry livestock management system under cut and carry livestock management system with group participation $(\mathrm{N}=\mathbf{4 0 0})$

About $66 \%$ of the 400 respondents completely agree with the statement, which means they state an expectation of enjoying benefits from cooperation. At the other extreme, $6 \%$ completely disagree.

\subsection{Sampled individual characteristics}

Descriptive statistics of respondent characteristics and spatial information for the four subwatersheds are presented in Table 2. About 2\% (nine individuals) of the respondents did not have any opinions, and these same individuals consistently chose the status quo alternative for

\footnotetext{
${ }^{7}$ In the first pre-test, most people selected "completely disagree" for the follow-up statement. However, following the adjustment of the definition of the cut and carry livestock management system (see section 2.2), we got an opposite response both in the second pre-test and the final survey.
} 
all nine choice sets presented to them, and provided inconsistent answers for several other questions in the questionnaire. They were therefore removed from the data before final analysis.

Table 2. Descriptive statistics $\mathbf{N}=391$

\begin{tabular}{|c|c|c|c|c|c|}
\hline & \multicolumn{5}{|c|}{ Mean (Std. Dev) } \\
\hline & Yetsed & Debrekelem & Gelila1 & Gelila2 & Total Sample \\
\hline Age & $\begin{array}{l}45.02 \\
(11.84)\end{array}$ & $\begin{array}{l}43.52 \\
(12.09)\end{array}$ & $\begin{array}{l}41.27 \\
(10.41)\end{array}$ & $\begin{array}{l}41.45 \\
(10.71)\end{array}$ & $\begin{array}{l}42.80 \\
(11.35)\end{array}$ \\
\hline Illiterate* & 0.38 & 0.49 & 0.45 & 0.63 & 0.49 \\
\hline Read and write* & 0.47 & 0.33 & 0.47 & 0.13 & 0.35 \\
\hline Elementary* & 0.13 & 0.15 & 0.07 & 0.21 & 0.14 \\
\hline High School and Above* & 0.02 & 0.02 & 0.01 & 0.02 & 0.02 \\
\hline Dependency ratio & 0.54 & 0.67 & 0.57 & 0.53 & 0.58 \\
\hline Off-farm business* & 0.44 & 0.68 & 0.21 & 0.07 & 0.35 \\
\hline Highly steep plot of land & $\begin{array}{l}0.94 \\
(0.97)\end{array}$ & $\begin{array}{l}0.89 \\
(0.84)\end{array}$ & $\begin{array}{l}0.41 \\
(0.66)\end{array}$ & $\begin{array}{l}1.70 \\
(1.06)\end{array}$ & $\begin{array}{l}0.98 \\
(1.00)\end{array}$ \\
\hline Labor cost & $\begin{array}{l}31.61 \\
(3.89)\end{array}$ & $\begin{array}{l}30.47 \\
(7.30)\end{array}$ & $\begin{array}{l}0.74 \\
(4.19)\end{array}$ & $\begin{array}{l}17.54 \\
(14.97)\end{array}$ & $\begin{array}{l}20.06 \\
(15.26)\end{array}$ \\
\hline Extra land use in $\mathrm{Kada}^{8}$ & $\begin{array}{l}-0.72 \\
(1.11)\end{array}$ & $\begin{array}{l}-1.47 \\
(1.19)\end{array}$ & $\begin{array}{l}-2.10 \\
(2.18)\end{array}$ & $\begin{array}{l}-1.08 \\
(0.75)\end{array}$ & $\begin{array}{l}-1.35 \\
(1.50)\end{array}$ \\
\hline
\end{tabular}

*0-1 Dummy variables

There are substantial differences across the four sub-watersheds in some variables, especially in terms of illiteracy proportions. Interesting variables are engagement in off-farm business, labor cost, and extra land use. In the Yetsed and Debrekelem regions a substantial proportion of individuals are engaged in off-farm activities. Similarly, in these two sub-watersheds, the average daily cost of labor is higher than in Gelila1 and Gelila2. In fact, the average reported labor cost is nearly zero in Gelila1, which is a somewhat surprising finding. People use less land for cultivation in Gelila1, which is explained by extra land use. Extra land use is defined as the difference between what the farmer cultivate minus the total land use right under his name. Farmers may cultivate more land by renting from others. The negative sign in extra land use shows that on average farmers use less land for cultivation than they own (Table 2).

\footnotetext{
81 kada is equal to 0.25 hectare. Extra land use is defined as the difference between what the farmer cultivate minus the total land use right under his/her name.
} 


\section{Theoretical modeling framework}

In this section, we first develop a theoretical framework that allows us to incorporate the farmer's expectations about the cooperation process into a utility function specification. By doing so we will show the role of these expectations in the way respondents' eliminate infeasible alternatives from the set of alternatives they consider (i.e., termed "choice set formation" by (Manski 1977, Swait 1984). Second, we discuss welfare measurement distortions resulting from farmers' doubts about cooperation outcomes. Finally, we will discuss approaches to measuring expectations. For details on measuring expectations in economic analysis see (Hurd 2009, Manski 2004, Delavande et al. 2011).

\subsection{Expectations of cooperation as a factor in screening of alternatives}

Expectations can be formed in various contexts. In most economic activities, rational economic agents' expectations about the future are reflected in current decisions, and correct representation of such expectations is important for designing and evaluating policy alternatives (Delavande et al. 2011, Wang 2014, Kassahun et al. 2016, Manski 2004, Bellemare 2009, Ostrom 2000). Expectations may be influenced by personal experience, social-norms, interactions with family members or friends, observation of others and receiving new information from different sources.

Whether agents' expectations are correct or incorrect, they affect current decision making. For example, Kassahun et al. (2016) show that farmers who decline to pay for reliable access to irrigation water have a lower perceived expectation of future irrigation productivity than stated

by domain experts. Similarly, expectations about premature death affect the decision of smokers (Wang 2014); and expectations about institutional trust determines citizen's WTP for the provision of public goods (Oh and Hong 2012). 
In the context of policy evolution about integrated land management involving common land, farmer's expectations regarding cooperation patterns and the benefit of cooperation play a significant role. Here, we are dealing with two main types of expectations. The first is about the trust in others that affects the expectation that those others will cooperate. The second is the expectation regarding the benefits resulting from the cooperation. By construction, following Ostrom (2000) for the steps for the development of successful trust and reciprocity, the first type can be integrated into a DCE design, for example in the way we have used it in our definition of the cut and carry livestock management option in this study ${ }^{9}$. Here, given trust that others will cooperate, the focus of the cooperation is on its expected benefits. The expected benefit of cooperation can be direct or indirect: a direct benefit if the cooperation leads to a direct financial gain/productivity improvement to the farmer, and an indirect benefit if the cooperation leads to a utility gain from reduction in negative externalities (i.e. the farmer holds some form of social preferences and derives utility from contributing to this). Nevertheless, in this article we do not distinguish between the two sources of expected benefits. Thus, farmers are assumed to add up all types of benefits and costs to come up with a decision when evaluating land management alternatives.

Let w1 through w4 represent the four erosion hot spot areas (sub-watersheds) ${ }^{10}$, each of which can be decomposed into 25 smaller geographical units, $g$, based on FDG. As noted earlier in

\footnotetext{
${ }^{9}$ Ostrom (2000) stated that "If a group of users can determine its own membership-including those who agree to use the resource according to their agreed-upon rules and excluding whose who do not agree to these rulesthe group has made an important first step toward the development of greater trust and reciprocity. " Likewise, Cavalcanti et al. (2013) noted that cooperation within a friendship-based social network relies on strong incentives to minimize socially unacceptable behavior such as free-riding, as strong friendships create an incentive not to cheat each other for fear of losing friendships and trust necessary for future collaboration. ${ }^{10} \mathrm{~A}$ watershed is an area or ridge of land that separates waters flowing to different rivers, basins, or seas.
} 
the case study, each $g$ represents a group of farmers who live on and own private agricultural land and have common land use rights within the boundary of each $g$ for livestock production in a free grazing system. The society faces two environmental problems from soil erosion from both private and common land: 1) on-site reduced soil productivity and 2) off-site impact such as irrigation or hydro reservoir sedimentation (negative externalities).

The utility $U_{n(w, g) j}$ for an integrated land management alternative $\mathrm{j}$ can be specified assuming that farmers within each $g$ collaborate on common land management (Kassahun and Jacobsen 2015), thus:

$$
\begin{aligned}
U_{n(w, g) j}= & \beta x_{1, n(w, g) j}+\rho_{1} q_{1, n(w, g) j}+\rho_{2} q_{2, n(w, g) j}+\rho_{3} q_{3, n(w, g) j}+ \\
& l_{1} L_{1, n(w, g) j}+l_{2} L_{2, n(w, g) j}+\varsigma_{1} k_{1, n(w, g) j}+\varsigma_{2} k_{2, n(w, g) j}+ \\
& \alpha_{j}+\varepsilon_{n(w, g) j}
\end{aligned}
$$

where $n$ is an individual, $w$ is a residential sub-watershed, $g$ is a social-spatial group, $\beta$ is a constant/average effect for the common land management option $j$, defined by $x_{1, n(w, g) j}$ being 1 for cut and carry livestock management system, otherwise 0 . Parameters $\rho_{1}, \rho_{2}$ and $\rho_{3}$ are the impacts for private land management options for Soil Bund with grass strip, $q_{1, n(w, g) j}$, Fanya Juu with grass strip, $q_{2, n(w, g) j}$, and Stone bund, $q_{3, n(w, g) j}$ respectively (Table 1). Parameter $l_{1}$ is the effect of labor contribution in days, $L_{1, n(w, g) j}$, while $l_{2}$ is a parameter of timing of labor contribution, $L_{2, n(w, g) j}=1$ for labor contribution equally distributed between the 12 Months, otherwise $0 . \varsigma_{1}$ is a parameter associated with additional extension services in days per year, $k_{1, n(w, g) j}$, and $\varsigma_{2}$ is a parameter for credit subsidy in Ethiopian Birr per year, $k_{2, n(w, g) j} . \alpha$ is the alternative-specific constant. Finally, $\varepsilon_{n(w, g) j}$ is an unobserved stochastic component with zero mean which is independently and identically distributed (iid) over alternatives and economic agents. 
The utility specification in Equation 1 is based on the restrictive and probably unrealistic assumption that individual farmers have equal expectations about the benefits of cooperation. In reality, individual farmers may differ in their expectations regarding mutual benefits of cooperation based on their own experience working, living and interacting with other farmers within the social and spatial group $g$. Consequently, if a farmer uses this subjective expectation about mutual benefits of cooperation in evaluating land management policy alternatives, using Equation 1 results in misrepresentation of the decision process.

Therefore, the utility function should be changed to reflect differences in expectations regarding mutual benefits from cooperation among farmers. Unfortunately, these expectations are usually unobservable by the researcher. Let these unobserved expectations about cooperation benefit be denoted by a latent variable $z_{n(w, g)}$. The distribution of $z_{n(w, g)}$ in the population may extend from negative infinity (expecting no cooperation at all) to positive infinity (full cooperation expectation), i.e. $(-\infty, \infty)$. For the sake of simplicity and convenience let the distribution of $z_{n(w, g)}$ be transformed to a scale varying between 0 and 1 using a logistic transformation (Equation 2), like so:

$$
\phi_{n(w, g)}=\frac{1}{1+\exp \left(\Gamma\left(-z_{n(w, g)}\right)\right)}
$$

where $\phi_{n(w, g)}$ is an expected cooperation index and $\Gamma$ is a scale parameter. The limits of the index are interpretable: $\phi_{n(w, g)}=0$ corresponds to no expected cooperation and $\phi_{n(w, g)}=1$ to full expected cooperation. If $\beta$ is associated with the highest benefits under full expected cooperation in common land management, doubt concerning expected cooperation, $\phi_{n(w, g)}<1$, may reduce the overall benefit of communal land management and lead to the overall rejection of the integrated land management options as $\phi_{n(w, g)}$ approaches zero. The logarithmic form is 
the most convenient functional form for introducing a penalty (discount factor) in the utility function (Martínez et al. 2009). Accordingly, the parameter associated with common land management becomes an individual-specific parameter adjusting the impact of expected cooperation benefit:

$\beta_{n}=\left(\beta+\lambda \log \left(\phi_{n(w, g)}\right)\right)$

where $\beta_{n}$ is the individual-specific parameter for common land management and $\lambda$ is a discount factor, which is greater than or equal to zero, to be estimated, and $\phi_{n(w, g)} \neq 0$. The attractiveness of the logarithm form is that when $\phi_{n(w, g)}$ approaches zero, $\log \left(\varphi_{n(w, g)}\right)$ goes to minus infinity, effectively making utility go to minus infinity. Note that from a policy perspective the individual farmer's doubts or skepticism about expected cooperation leads to reduced expected utility from engaging in integrated land management (Equation 3). Substituting $\beta$ (Equation 1) with Equation 3 gives us the expected cooperation adjusted utility function, for convenience we have removed all subscripts, $n(w, g) j$, from the variables.

$$
\begin{aligned}
U_{n(w, g) j}= & \beta_{n} x_{1}+\rho_{1} q_{1}+\rho_{2} q_{2}+\rho_{3} q_{3}+l_{1} L_{1}+l_{2} L_{2}+\varsigma_{1} k_{1}+\varsigma_{2} k_{2}+ \\
& \alpha_{j}+\varepsilon_{n(w, g) j}
\end{aligned}
$$

We further elaborate on the modelling framework by hypothesizing that spatial and social factors are more alike within the same geographical area, and consequently, the choices of individuals within the boundary are more likely to be correlated. Following Bhat (2000) on multistage spatial clustering of observations in discrete choice modeling, we adjust Equation (4) to account for two-stage spatial correlation. The first stage accounts for agents who share watershed or political administrative unit, and the second stage for agents who share joint common land and have lived within the boundary of $g$ for many years. 


$$
\begin{aligned}
U_{n(w, g) j}= & \beta_{n} x_{1}+\rho_{1, n} q_{1}+\rho_{2, n} q_{2}+\rho_{3, n} q_{3}+l_{1},_{n} L_{1}+l_{2} L_{2}+\varsigma_{1} k_{1}+\varsigma_{2} k_{2}+ \\
& \alpha_{j}+\omega^{\prime} w_{w}+\eta_{g}+\varepsilon_{n(w, g) j}
\end{aligned}
$$

where $\omega^{\prime}$ is a vector of parameters to be estimated associated with watersheds $w_{w}$, and $\eta_{g}$ are group-specific " $g$ " random disturbance terms normally distributed with mean 0 and variance $\sigma_{\eta}^{2}$. The introduction of $\eta_{g}$ controls for possible unobserved spatial and social factors common among individuals who share joint common land within the same geographical area in a close social network. Furthermore, considering the variation in topography and labor availability, at this stage it is also rational to assume an individual specific parameter for private land management options $\left(\rho_{1, n} ; \rho_{2, n} ; \rho_{3, n}\right)$ and timing of labor contribution, $l_{1, n}$.

\subsection{Welfare measurement}

Given the utility specification in Equation (5), we derive the compensating variation (CV) measures of welfare change both in terms of money and labor contribution. Eom and Larson (2006) have provided the theoretical framework of welfare measurement for a change in environmental quality using monetary and labor contributions in areas where there is a scarcity of money and labor (for an application example see Gibson et al. (2016) and Rai and Scarborough (2013). In our case, since the change in livestock management system from free grazing to cut and carry livestock manage system is a key policy interest and dependent on the level of farmers' expected cooperation, the ultimate welfare impact of the change in land management practice is individual specific. Let $u_{n j}^{0}$ be the utility for an alternative $j$ under free grazing livestock management system $x_{1}^{0}$, and $u_{n j}^{1}$ be the utility of alternative $j$ under cut and carry livestock management system $x_{1}^{1}$. The CV measure of welfare is given by equating $u_{n j}^{0}$ and $u_{n j}^{1}$.

$u_{n j}^{0}=u_{n j}^{1}$ 
$\beta_{n} x_{1}^{0}+l_{2} L_{2}+\varsigma_{2} k_{2}+A=\beta_{n} x_{1}^{1}+l_{2} L_{2}+\varsigma_{2}\left(k_{2}+C V^{M}\right)+A$

where $A$ is the utility of all other attribute which is the same before and after the change in livestock management system. By rearranging equation $6 \mathrm{~b}$, we obtain the monetary measure of welfare, $C V^{M}$ :

$$
C V^{M}=\frac{\beta_{n} x_{1}^{0}-\beta_{n} x_{1}^{1}}{\varsigma_{2}}=-\frac{\beta_{n} x_{1}^{1}}{\varsigma_{2}}=-\frac{\left(\beta+\lambda \log \left(\varphi_{n(w, g)}\right)\right)}{\varsigma_{2}}
$$

If the change from free grazing to cut and carry livestock system leads to a negative welfare change, i.e., $\beta+\lambda \log \left(\varphi_{n(w, g)}\right)<0, C V^{M}$ can be interpreted as willingness to accept (WTA), which is equivalent to the amount of compensation needed to make the person indifferent between $u_{n j}^{0}$ and $u_{n j}^{1}$ (Equation 6a). If $\beta>0$ and $\beta>\left|\lambda \log \left(\varphi_{n(w, g)}\right)\right|, C V^{M}$ is interpreted as willingness to pay (WTP).

Given Equation 6a, the CV measure of welfare can be expressed in terms of labor contribution.

$\beta_{n} x_{1}^{0}+l_{2} L_{2}+\varsigma_{2} k_{2}+A=\beta_{n} x_{1}^{1}+l_{2}\left(L_{2}+C V^{W}\right)+\varsigma_{2} k_{2}+A$

By rearranging Equation 6d, we obtain the CV measure of labor contribution in Equation 6e .

$$
C V^{W}=-\frac{\left(\beta+\lambda \log \left(\varphi_{n(w, g)}\right)\right)}{l_{2}}
$$

If $\beta+\lambda \log \left(\varphi_{n(w, g)}\right)>0, C V^{W}$ is interpreted as willingness to contribute (WTC) labor. In this case, $C V^{W}$ is the number of days of labor contribution to make the person indifferent between $u_{n j}^{0}$ (free grazing livestock management system) and $u_{n j}^{1}$ (cut and carry livestock management system.

However, if $\beta+\lambda \log \left(\varphi_{n(w, g)}\right)<0$, the person needs a compensation to implement the cut and carry livestock management system. Given Equation $6 \mathrm{~b}$ and Equation $6 \mathrm{~d}$, we can calculate that 
the monetary equivalent of labor contribution compensation. Note that the left sides of Equation $6 \mathrm{~b}$ and Equation $6 \mathrm{~d}$ are equal. Accordingly, we can write

$\beta_{n} x_{1}^{1}+l_{2} L_{2}+\varsigma_{2}\left(k_{2}+C V^{M}\right)+A=\beta_{n} x_{1}^{1}+l_{2}\left(L_{2}+C V^{W}\right)+\varsigma_{2} k_{2}+A$,

and solving for $C V^{M}$ gives Equation $6 \mathrm{f}$.

$C V^{M}=\frac{l_{2}}{\varsigma_{2}} C V^{W}$

where $l_{2} / \varsigma_{2}$ is the shadow price of labor. The shadow price provides flexibility for exchange of money and labor as a payment vehicle.

Note that with full expected cooperation $\left(\phi_{n(w, g)}=1\right)$ in Equation $6 \mathrm{c}$ or Equation $6 \mathrm{e}$, there is no choice set screening process based on expectations of cooperation on common land management. Farmers evaluate common land management based on other criteria. If there is skepticism about expected cooperation, the gain obtained from participating in the cut and carry livestock management system is reduced by a factor of $\lambda \log \left(\varphi_{n(w, g)}\right) / \varsigma_{2}$. This has important policy implications: ceteris paribus, as the level of expected cooperation declines, the likelihood of an individual participating in an integrated land management type declines. Further, if implementing the integrated land management is a necessary condition, individual farmers may require a substantial subsidy or other incentives to offset the negative effects of high doubts about expected cooperation. This can be demonstrated using an example. Let $\beta=1$ $, \lambda=2, \varsigma_{2}=0.002$, and $l_{2}=-0.014$ in Equation (6b). If the farmer expected full cooperation on common land management, he is willing to pay $\$ 500$ or contribute 71.4 days of labor to be part of the integrated land management (Equation 6c). In contrast, if the farmer has low expectations to mutual benefits from cooperation, his/her WTP will be lower than $\$ 500$. For 
all values $\phi_{n}<0.32$, the farmer requires a compensation to participate in the common land management scheme, and the compensation requirement grows exponentially as the farmer's expectations to mutual benefits from cooperation approach zero (Figure 4). Likewise, when $\phi_{n}>0.32$ a negative WTA means that the farmer will engage on his own in integrated land management and be willing to pay (carry a cost) up to his WTP, which is equivalent to the amount of his labor contribution to implement the management plan, given by Equation 6e or Equation 6f.

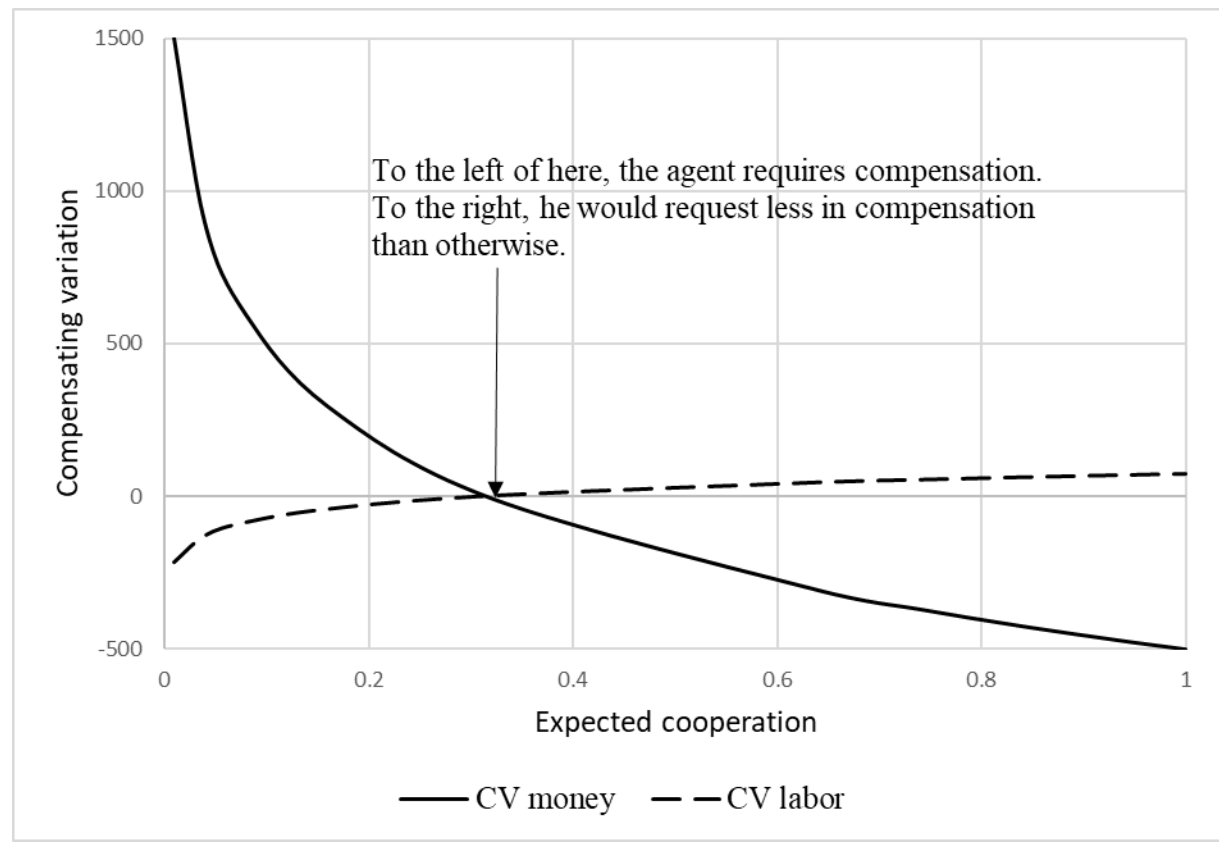

Figure 4. Example of the relationship between compensating variation and expected benefits from cooperation where 1 refers to full benefit, and 0 to no benefit

\section{Measuring expectations}

To avoid potential measurement error, we treat farmers' expectation of cooperation as a latent variable and the face value of subjective belief (Figure 3) is used as an indicator of such latent 
expectations $^{11}$. Accordingly, the latent expectations of cooperation, $z_{n}$, and its indicator function are defined in Equation (7) and Equation (8), respectively.

$$
z_{n(w, g)}=d+\sum_{\theta=1}^{\Theta} \theta S_{n(w, g)}+\eta_{g}+v_{n}
$$

where $d$ is a constant to be estimated, $\theta$ is a vector of parameters to be estimated, $S_{n(w, g)}$ is a vector of variables linked to individual characteristics and/or spatial characteristics, $\eta_{g}$ is already defined in Equation (5), and ${ }^{v_{n}}$ is a random disturbance term iid over agents. Assuming that the indicator, $y_{n(w, g)}$, is categorical with an M point scale and $v_{n}$ is logistic distributed, the probability of observing $y_{n(n, g)}=m, m=1,2, \ldots, M$ can be modeled conditional on the distribution of the latent variable $z_{n}$, as below:

$$
\begin{aligned}
& \varphi\left(y_{n(n, g)}=\left.1\right|^{z_{n(w, g)}}\right)=\left(\frac{1}{1+e^{\gamma z_{n(w, g)}}}\right) \\
& \varphi\left(y_{n(n, g)}=\left.2\right|^{z_{n(w, g)}}\right)=\left(\frac{1}{1+e^{\gamma z_{n(w, g)}-\tau_{2}}}\right)-\left(\frac{1}{1+e^{\gamma z_{n(w, g)}}}\right) \\
& \vdots \\
& \varphi\left(y_{n(n, g)}=\left.M\right|^{\left.z_{n(w, g)}\right)}\right)=1-\left(\frac{1}{1+e^{\gamma z_{n(w, g)}-\tau_{m-1}}}\right)
\end{aligned}
$$

\footnotetext{
${ }^{11}$ In the literature there are two methods for measuring and eliciting subjective expectations: 1) nonprobabilistic and 2) probabilistic. The non-probabilistic way of measuring expectations usually uses a scale that measures the likelihood of a perceived event occurring, or alternatively economic agents are asked to state their strength of belief that an event will occur. However, this method of eliciting subjective expectations is prone to measurement error (Manski 2004). The other method for eliciting expectations is the probabilistic method: economic agents are directly asked to report their expectation in probabilistic form. The probabilistic method is considered advantageous for measuring directly the probabilities. Nevertheless, if agents are unable to express their expectation in probabilistic form, the same measurement error issues will arise.
} 
where $\gamma$ is factor loading and $\tau$ is a vector of threshold values (M-1 threshold values are identifiable, or equivalently M-2 threshold values are identified if a constant is estimated in either Equations 7 or 8).

\section{Empirical model specification, model identification and estimation}

In section 3 we developed the theoretical framework for an econometric model of implicit choice set formation that accounts for farmers' expectations regarding cooperation in an integrated private and common land management system. The empirical model presented here includes the structural model that explains latent expectations of cooperation (Equation (7)), the measurement model for expectations of cooperation indicator (Equation (8)), the structural model that explains utility accounting for skepticism in expected cooperation, and measurement models that explain choice. To reiterate, the operative behavioral mechanism whereby skepticism arising from expectations of cooperation acts is through the screening/elimination of the common land management system alternatives.

\section{Structural and measurement model for expected cooperation}

The measurement model for expected cooperation indicator is defined in Equation (8). Here, we emphasize the structural model for expected cooperation. We define the structural latent expectation of cooperation as a function of social and spatial variables in Equation (7). These social and spatial variables are listed in Table 2. Age is hypothesized to have a negative effect on expected cooperation for a joint "cut and carry" livestock management system, because the basis of the cooperation is an equal contribution of labor and benefits; since older individuals may not have the energy to contribute the required amount of labor even if they support the idea of cooperation, increased age will be expected to reduce cooperation. Furthermore, in the study area, there is also evidence that female-headed (widowed) and old farmers are renting out their land as an alternative way of making a livelihood (Kassahun and Jacobsen 2015), 
which supports the hypothesis of a negative relationship between labor-intensive cooperation and an increase in age. Dependency ratio (the ratio of economically dependent households per economically active households ${ }^{12}$ ) is hypothesized to have a negative effect on cooperation, as extra labor is demanded to manage within-household subsistence. Engagement on off-farm activity may have either a positive or negative effect depending on the extent of the benefit between the off-farm business and cooperation for livestock production. Similarly, extra land use may have either positive or negative effects on expected cooperation depending on benefit differential.

An increase in local labor cost is hypothesized to have a positive effect on social cooperation as an alternative means of acquiring labor. This is true in rural areas of developing countries, where most people do not supply labor to the market (Barrett et al. 2008). Finally, the number of very steep plots of land is hypothesized to have a positive effect on expected cooperation for a joint "cut and carry" livestock management system, as the cost of crop production increases with the gradient of landscape for two main reasons. First, the impact of soil erosion is intensified on sloping land, which results in loss of soil nutrients and increases the need for artificial fertilizers (Pimentel 2006, Pimentel et al. 1995). Second, the amount of labor time required to prepare cropland increases with the slope of the landscape. Furthermore, farmers with steeper land plots have probably suffered more from erosion problems in the past and therefore are more aware of the problem. Thus, we expect that having a steeper plot of land leads to positive cooperation for a joint "cut and carry" livestock management system.

\section{Structural and measurement model for utility}

\footnotetext{
${ }^{12}$ Economically dependent households are individuals under the age of 12. Economically active household is a household member above the age of 12 to 65 years.
} 
The utility specification accounting for expectations about cooperation is presented in Equation (5). The specification allows multistage spatial clustering of observations and correlations in a cross-sectional data context. Given that the empirical data consists of repeated choices from the DCE, by allowing the estimation of individual specific constant, $\alpha_{n}$, the utility equation is adjusted to accommodate potential error correlation over choice tasks $t$ :

$$
\begin{aligned}
& U_{n(w, g) j t}=\beta_{n} x_{1 t}+\rho_{1, n} q_{1 t}+\rho_{2, n} q_{2 t}+\rho_{3, n} q_{3 t}+l_{1} L_{1 t}+l_{2, n} L_{2 t}+\varsigma_{1} k_{1 t}+\varsigma_{2} k_{2 t}+ \\
& \quad \alpha_{n}+\omega^{\prime} w_{w}+\eta_{g}+\varepsilon_{n(w, g) j t} \\
& \alpha_{n} \square\left(\bar{\alpha}, \sigma_{\alpha}^{2}\right)
\end{aligned}
$$

where $\bar{\alpha}$ and $\sigma_{\alpha}^{2}$ are mean and variance of $\alpha_{n}$. Let the systematic component utility in equation 9 represented by $V_{n(w, g) j t}$. Accordingly, equation (9) can be rewritten as:

$$
U_{n(w, g) j t}=V_{n(w, g) j t}+\eta_{g}+\varepsilon_{n(w, g) j t}
$$

Assuming $\varepsilon_{n(w, g) i t}$ is iid Gumbel over alternatives, task, people and space in Equation 10, the measurement model for the choice indicator $\left(\delta_{i n(w, g) t}\right)$ for an alternative $i$ individual $n$ in the t'th choice situation can be expressed as:

$\delta_{i n(w, g) t}=\left\{\begin{array}{l}1, \text { if } U_{n(w, g) i t}=\max _{j \in C_{n(w, g) t}}\left\{U_{j(w, g) n t}\right\} \\ 0, \text { otherwise }\end{array}\right.$

where $C_{n(w, g) t}$ is the set of alternatives presented to individual $n$ at choice task $t$. The unconditional choice probability of the sequence of $\mathrm{T}$ choices is given by integrating over the random variables:

$$
\begin{gathered}
\pi(\delta)=\int \prod_{t=1}^{T} \frac{\exp \left(\Gamma_{n(w)}^{\prime}\left(V_{n(w, g) i t}+\eta_{g}\right)\right)}{\sum_{j \in C_{n t}} \exp \left(\Gamma_{n(w)}^{\prime}\left(V_{n(w, g) j t}+\eta_{g}\right)\right)} \\
f_{1}\left(z_{n} \mid S_{n(w, g)}, \eta_{g(n)}\right) f_{2}(\eta) f_{3}(\mu) f_{4}(\rho) f_{5}(l) d z d \eta d \mu d \rho d l
\end{gathered}
$$


where $\Gamma_{n(w)}^{\prime}$ is a vector of watershed scale parameters. $f_{1}\left(z_{n} \mid S_{n}, \eta_{g}\right), f_{2}(\eta), f_{3}(\mu), f_{4}(\rho)$ and $f_{5}(l)$ are the density of expected cooperation, $\eta, \mu, \rho$ and $l$ respectively, and specified to be normal. Following Swait and Louviere (1993), when data for analysis comes from different regions, it is recommendable to allow for regional differences in scale. Thus, we estimate scale parameters for different watersheds.

\section{Identification and model estimation}

So far we have discussed the components of the land management choice model and the cooperation indicator model. These model components can be estimated sequentially. However, a number of authors have indicated that sequential model estimation might lead to lower statistical efficiency (Ben-Akiva et al. 1999, Hess and Beharry-Borg 2012). Therefore, in this article we implement full information model estimation. Accordingly, the unconditional probability of observing the joint sequence of choice (Equation (12)) and observed indicator of cooperation (Equation (8)) is given by:

$$
\begin{gathered}
\pi(\delta, y)=\int \prod_{t=1}^{T} \frac{\exp \left(\Gamma_{n(w)}^{\prime}\left(V_{n(w, g) i t}+\eta_{n(g)}\right)\right)}{\sum_{j \in C_{n t}} \exp \left(\Gamma_{n(w)}^{\prime}\left(V_{n(w, g) j t}+\eta_{n(g)}\right)\right)} \phi\left(y_{n(w, g)} \mid z_{n(w, g)}\right) \\
f_{1}\left(z_{n} \mid S_{n(w, g)}, \eta_{g(n)}\right) f_{2}(\eta) f_{3}(\mu) f_{4}(\rho) f_{5}(l) d z d \eta d \mu d \rho d l
\end{gathered}
$$

where $\pi(\delta, y)$ is the joint probability of choice and observed indicators of cooperation. Estimation of Equation (13) requires normalizing either the error variance of the latent variable model (Equation (7)) or one of the indicator parameter estimates, $\gamma$ in Equation (8). Vij and Walker (2014) suggested a third approach by constraining the coefficient of the latent variable in the utility equation. For a detailed discussion see Daly et al. (2012) and Vij and Walker (2014). We normalize $\gamma$ to unity. Accordingly, the log likelihood of the sample is specified as: 


$$
\begin{aligned}
L L(\delta, y)=\sum_{n=1}^{N} \log \int \prod_{t=1}^{T} \frac{\exp \left(\Gamma_{n(w)}^{\prime}\left(V_{n(w, g) i t}+\eta_{n(g)}\right)\right)}{\sum_{j \in C_{n t}} \exp \left(\Gamma_{n(w)}^{\prime}\left(V_{n(w, g) j t}+\eta_{n(g)}\right)\right)} \phi\left(y_{n(w, g)} \mid z_{n(w, g)}\right) \\
f_{1}\left(z_{n} \mid S_{n(w, g)}, \eta_{g(n)}\right) f_{2}(\eta) f_{3}(\mu) f_{4}(\rho) d z d \eta d \mu d \rho
\end{aligned}
$$

where $n=1, \ldots, N$ is a respondent index. In Equation (2) and Equation (12), we have specified a scale parameter $(\Gamma)$ and a vector watershed scale parameters $\left(\Gamma^{\prime}\right)$ respectively. For identification purposes, we normalize the scale of one of the sub watersheds to unity to allow the estimation of three sub-watershed scale parameter and $\Gamma$. Finally, Equation (14) is estimated via a maximum simulated likelihood estimation procedure in the Python Biogeme Software (Bierlaire and Fetiarison 2009). From this point, we refer to our model as our proposed model, also termed the Social-spatial Group-Adjusted Implicit Choice Set Formation (SG-CSF) model.

\section{Comparing model fit and welfare measures across models}

One particular point we wish to explore is to compare whether policy conclusions depends on the model specification. Note that McFadden and Train (2000) showed that with mild variation in a specification, the mixed logit model can approximate the choice probability of any discrete choice model. Therefore, we compare the proposed model with the structural latent class model used by Kassahun and Jacobsen (2015) and a social-spatial group-adjusted mixed logit (SGMXL). The functional form of the SG-MXL is the same as our proposed model apart from the parameter associated with livestock management system, which is treated as a random parameter in SG-MXL. Furthermore, SG-MXL does not require the estimation of the cooperation indicator model. As the models are non-nested, we focus on the predictive power of models, and the Pearson's chi-Squared ratio is used for assessment of model performance (Swait et al. 1994). The Pearson's chi-Squared ratio is given by: 
$P=\sum_{j=1}^{C}\left(\frac{\delta_{i n(w, g) t}-\hat{\delta}_{i n(w, g) t}}{\sqrt{\hat{\delta}_{i n(w, g) t}\left(1-\hat{\delta}_{i n(w, g) t}\right)}}\right)^{2} /(C-N-K)$

where $P$ is the Pearson's chi-Squared ratio, $\hat{\delta}$ is predicted probability for the alternative. $C$ is the number of alternatives from all choice sets over all $N$ respondents, and $K$ is the number of parameters estimated in the model. The reason to adopt the Pearson's chi-squared ratio as a basis for model comparison is that it is based upon the residuals, which contain information about the mis-prediction behaviour of a model. We believe this makes for a more solid basis for model selection than log likelihood-based measures.

If we use prediction power as a base for models comparison, it is important to evaluate how our proposed model performs compared to other alternative models available for prediction and welfare estimates. Any difference accounted for between the SG-MXL and our proposed model is essentially due to the inclusion of choice set formation in the latter. Thus, we will provide a detailed account of the expected welfare estimates of the livestock management system between the two models by a simulation approach.

\section{Results and Discussion}

The results of the proposed model estimation of Equation (14) are presented in Table 3. We used 3,000 Modified Latin Hypercube Sampling (MLHS) draws to estimate the model (Hess et al. 2006). Parameter estimates of the model are stable above 500 MLHS draws. Similarly, we used 3,000 MLHS draws to estimate the SG-MXL model (Appendix B for results). The value of Pearson's chi-Squared ratio shows that both our proposed model and the SG-MXL are superior in terms of prediction power compared to the structural latent class model used in Kassahun and Jacobsen (2015) on the same dataset. Our proposed model and the SG-MXL model have comparable Pearson's chi-Squared ratio values of 0.93 and 0.99 , respectively, 
compared to 2.49 for the latent class model. A discussion about welfare estimate comparison will follow after we report the findings of the proposed model in Table 3.

The estimation results presented in Table 3 have three components. Panel A presents the parameter estimates of the latent expectation of cooperation model, Panel B presents the measurement model parameters for the stated cooperation expectation indicator, and Panel $\mathrm{C}$ displays the parameter estimates of the choice model with an implicit penalty arising from expected cooperation.

Table 3. Model Estimates ( proposed model)

Panel A- The parameter estimates of the latent expectation of cooperation

\begin{tabular}{llll}
\hline Name & Value & Robust Std err & p-value \\
\hline$d$ & 4.920 & 0.71 & 0.00 \\
Age & -0.034 & 0.01 & 0.00 \\
Illiterate & 0.000 & & \\
Read and write & 0.638 & 0.24 & 0.01 \\
Elementary & 0.997 & 0.34 & 0.00 \\
High school above & 1.100 & 1.02 & 0.28 \\
Dependency ratio & -0.297 & 0.24 & 0.22 \\
Off-farm business & -0.195 & 0.25 & 0.43 \\
Labor cost & 0.022 & 0.01 & 0.01 \\
Steep plot of land & 0.275 & 0.13 & 0.03 \\
Extra land use & 0.072 & 0.06 & 0.25 \\
$\sigma_{g}$ & 1.900 & 0.23 & 0.00 \\
\hline
\end{tabular}

Panel B-The measurement model parameters for stated cooperation expectation indicator

\begin{tabular}{llll}
\hline Name & Value & Robust Std err & p-value \\
\hline$\gamma$ & 1 & & \\
$\tau_{1}$ & 0 & & \\
$\tau_{2}$ & 1.910 & 0.28 & 0.00 \\
$\tau_{3}$ & 3.050 & 0.34 & 0.00 \\
\hline
\end{tabular}


Table 3. continued

Panel $C$ - the parameter estimates of the choice model with a constraint in expected cooperation

\begin{tabular}{|c|c|c|c|}
\hline Name & Value & Robust Std err & p-value \\
\hline$\Gamma_{n(1)}^{\prime}$ & 1.000 & & \\
\hline$\Gamma_{n(2)}^{\prime}$ & 0.828 & 0.15 & 0.00 \\
\hline$\Gamma_{n(3)}^{\prime}$ & 0.499 & 0.08 & 0.00 \\
\hline$\Gamma_{n(4)}^{\prime}$ & 0.391 & 0.07 & 0.00 \\
\hline $\bar{\alpha}$ & 10.300 & 1.69 & 0.00 \\
\hline$\sigma_{\alpha}$ & 6.900 & 1.19 & 0.00 \\
\hline Soil bund with grass strip & 0.794 & 0.13 & 0.00 \\
\hline Stone bund & 0.789 & 0.13 & 0.00 \\
\hline Fanya Juu with grass strip & 0.145 & 0.09 & 0.09 \\
\hline Livestock production system & 14.000 & 6.02 & 0.02 \\
\hline discount factor multiplier, $\ln (\lambda)$ & 3.500 & 0.24 & 0.00 \\
\hline Scale for expected collaboration, $\ln (\Gamma)$ & -1.580 & 0.46 & 0.00 \\
\hline Labour contribution & -0.031 & 0.01 & 0.00 \\
\hline Time preference of labour contribution & 1.290 & 0.20 & 0.00 \\
\hline Additional extension service per year & 0.063 & 0.02 & 0.00 \\
\hline Subsidy per year & 0.004 & 0.00 & 0.00 \\
\hline \multicolumn{4}{|l|}{ Standard deviation } \\
\hline Soil bund with grass strip & 0.445 & 0.22 & 0.04 \\
\hline Stone bund & 0.959 & 0.16 & 0.00 \\
\hline \multicolumn{4}{|l|}{ Table 3. continued } \\
\hline Time preference of labour contribution & 1.160 & 0.22 & 0.00 \\
\hline$w_{1}$ & -4.190 & 1.34 & 0.00 \\
\hline$w_{2}$ & -4.170 & 1.36 & 0.00 \\
\hline$w_{3}$ and $w_{4}$ & 0.000 & & \\
\hline \multicolumn{4}{|l|}{ Model Statistics } \\
\hline No. of MLHS draws & 3000 & & \\
\hline Sample size & 3519 & & \\
\hline No. individuals & 391 & & \\
\hline No. of estimated parameters (K) & 33 & & \\
\hline Final log likelihood (FLL) & -2460.11 & & \\
\hline Pearson's chi-Squared ratio & 0.93 & & \\
\hline
\end{tabular}




\section{Parameter estimates of latent expectation of cooperation model}

As hypothesized, an increase in age has a negative effect on the expected cooperation for a joint "cut and carry" livestock management system. Farmers with a capacity to read and write or with elementary education have a more positive expectation regarding cooperation compared to illiterate individuals. However, there is no difference between illiterates and individuals with high school or above background. As expected, an increase in local labor cost and having a larger proportion of steep agricultural land is positively associated with higher expectations of cooperation (Panel A). However, as we have noted earlier, there is no conclusive evidence regarding the importance of engagement in off-farm and extra land use activities for expectations regarding cooperation. Group social-spatial unobserved characteristic $\eta_{g}$, which is jointly specified with the choice model, is highly significant. This confirms that the choices of individual farmers are indeed not independent from choices of other farmers in their social-spatial group. This justifies the core of our social-spatial model components.

\section{Parameter estimates for the measurement model}

In the measurement model (an ordered logistic model) we describe how the cooperation expectations indicator is related to the underlying latent cooperation expectation; the factor loading $\gamma$ is fixed to 1 (Panel B). This allows direct interpretation of the parameters of the latent variable model (Panel A) as determinants of the indicator model. In addition, we are able to estimate two thresholds (Tau2 and Tau3), while holding Tau1 fixed to 0 to allow the estimation of the constant in the latent variable (cooperation benefit expectations) model (Panel A). The thresholds are highly significant and increasing in magnitude, as expected.

Parameter estimates of the choice model with constraint in expected cooperation 
The parameter estimates of the choice model with expected cooperation constraints are presented in Table 3 (Panel C). All parameters associated with private and common land management are significant. The significant parameters associated with sub-watershed scales $\Gamma_{n(w)}^{\prime}$ demonstrate the importance of accounting for scale (error variance) heterogeneity across the four sub-watersheds. Scale variation might be due to several factors, which are not modelled explicitly here. Parameters associated with individual specific constants, the mean $\bar{\alpha}$ and standard deviation $\sigma_{\alpha}$, are highly significant. We note the positive and large relative magnitude of the mean estimate, implying that ceteris paribus farmers prefer policy-designed alternatives to the status quo alternative. However, farmers from $w_{1}$ (Yetsed) and $w_{2}$ (Debrekelem) are less likely to prefer policy-designed alternatives compared to those from $w_{3}$ (Gelila1) and $w_{4}($ Gelila2).

Of particular interest in the utility function are the parameters involving the choice of livestock production system and the cooperation constraint, because they relate directly to the management of common land. The livestock production system variable is coded as a dummy variable, where 1 represents a "cut and carry" livestock production system and 0 represents a free grazing system. Thus, the parameter reflects the preference for the collaborative option relative to the competitive one. The parameter of the "cut and carry" livestock production system is positive and significant at the $5 \%$ significance level. However, for individuals with doubts about cooperation levels, both the magnitude and the sign of "cut and carry" livestock production system parameter cannot be interpreted alone without adjusting for the cooperation constraint effect. The adjusted individual-specific parameters for "cut and carry" livestock management system are presented together with the total penalty associated with skepticism about expected cooperation in Figure 5. 


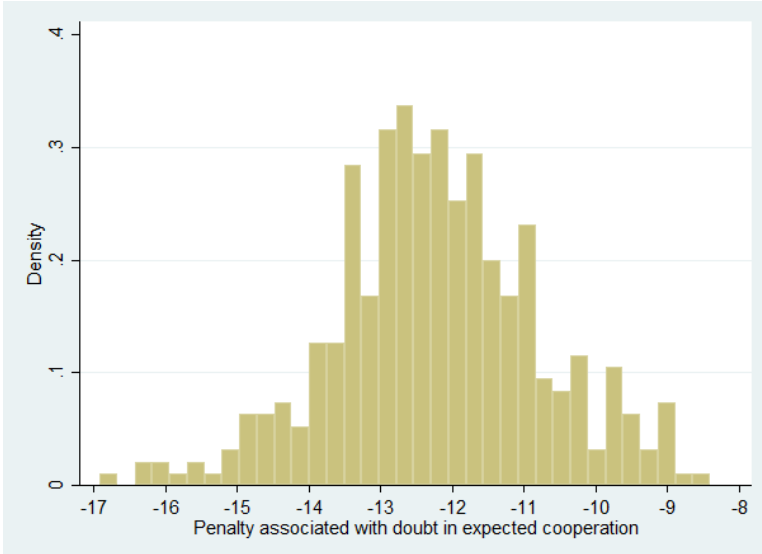

Panel I

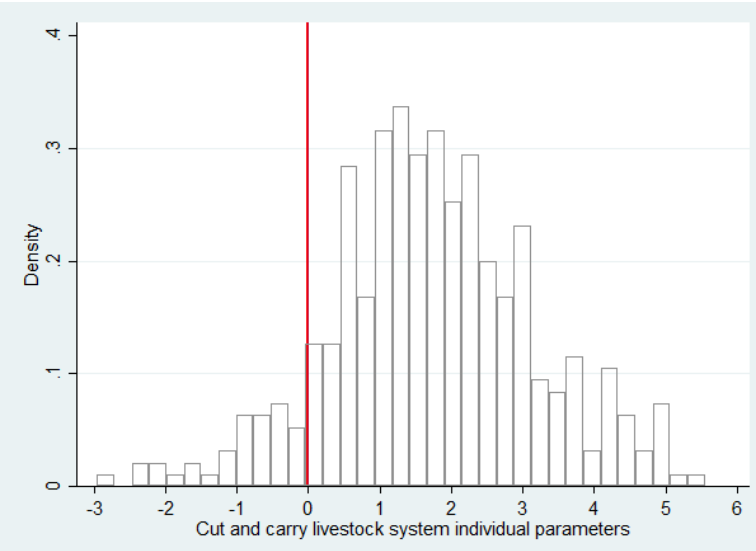

Panel II

Figure 5. Density estimate for penalty associated with doubt in expected cooperation and cut and carry livestock system

Figure 5 Panel I presents a density plot for the penalty associated with skepticism in expected cooperation for "cut and carry" livestock management system. With penalty values ranging between -16.91 and -8.40 , the result shows that no farmer in the sample holds fully positive expectations regarding cooperation in the "cut and curry" livestock management system. Figure 5 Panel II presents the density of individual specific parameters for "cut and carry" livestock system adjusted for the associated utility penalty in Panel I (Equation (3)). The result reveals that about $9 \%$ percent of farmers (i.e. the region to the left of the vertical reference line in Panel II) have a negative preference for "cut and carry" livestock management system.

The parameter estimates of the latent expected cooperation lead us to conclude that age has a pivotal role in explaining negative preferences (Figure 6, Panel I). In an economic context, this means that the welfare benefit of engaging in a collaborative livestock management scheme declines as the age of an individual farmer increases, so that eventually the welfare gain from engaging in the collaborative livestock management becomes negative (age above 65 years). In such circumstances, farmers need a substantial amount of compensation in order to allocate their scarce time for collaborative livestock management, as can be seen in the graphical 
illustration of the calculated welfare estimate for "cut and carry" livestock system (Figure 6, Panel II ${ }^{13}$. If we compare age groups 20 to 30 with 50 to 60 , the willingness to contribute labor for cut and carry livestock system declines approximately by $68 \%$.

Similarly, the number of highly steep plots of land has a significant role in shaping expectations about social cooperation benefits. This is likely a result of production and physical labor requirements for crop production increasing with the gradient of landscape. This makes the alternative "cut and carry" livestock management system more attractive with regard to crop production on marginal lands. Figure 6 Panel III displays the relationship between utility penalty and the number of highly steep plots of land: as this number increases the utility penalty declines, and individuals are willing to allocate more labor time for collaborative "cut and carry" livestock management systems and need less subsidy (Figure 6 Panel IV). The willingness to contribute labor increases by $52 \%$ if the individual has a very steep plot of land compared to a person endowed with flat land. Thus, initial policy implementation targeting areas dominated with steep plots of land has advantages for policy acceptance.

In addition to the sensitivity of welfare impacts presented in Figure 6, the mean, the standard deviation, and the confidence interval welfare estimates for "cut and carry" livestock management system is provided in Table 4 for the sample population. On average, farmers are willing to contribute 56 days of labor and less subsidy (i.e., equivalent to 387 Ethiopian Birr) ${ }^{14}$.

\footnotetext{
${ }^{13}$ The willingness to contribute (WTC) labor and the willingness to accept (WTA) subsidy are calculated as the negative ratio of the cut and carry livestock management system parameters' to the labor contribution and subsidized loan coefficient, respectively (Equation 6). Both subsidized loans and labor contributions are highly significant with the expected sign.
}

$141 \mathrm{ETB}=0.06 \mathrm{USD}$ 
Nevertheless, the range of this estimate is considerable with some farmers willing to allocate from -96 to 180 days per year for livestock production system (Figure 7), while others need a substantial subsidy - up to 660 ETB - to engage in this system. The negative value in labor contribution reflects the farmers who are not willing to contribute labor, however if a subsidy of 660 ETB is provided farmers are willing to contribute 96 days of labor per year.
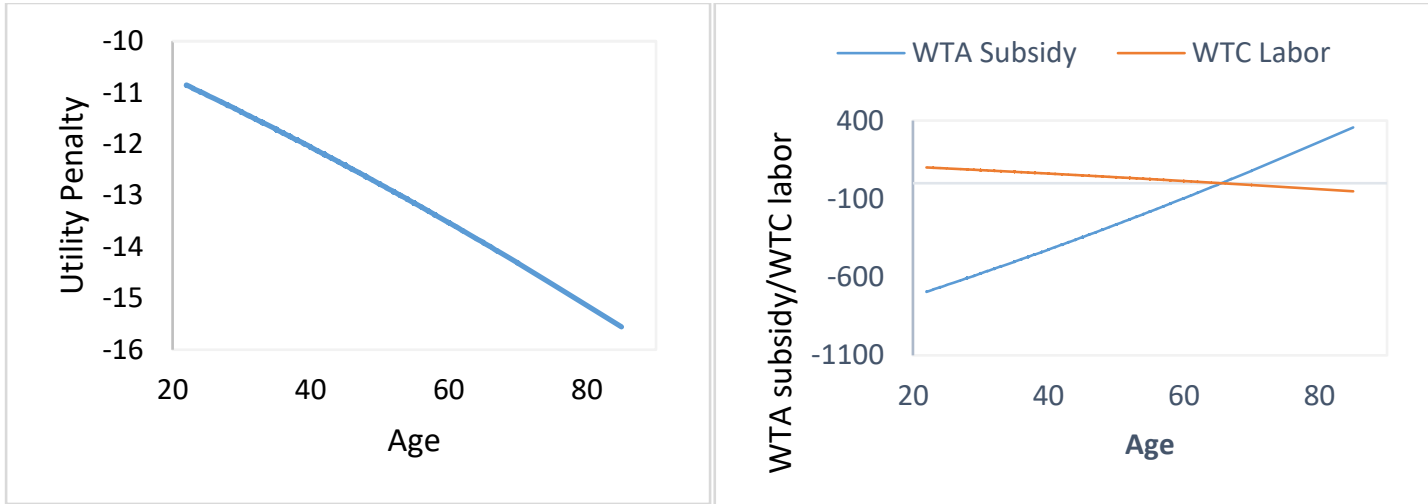

Panel I

Panel II

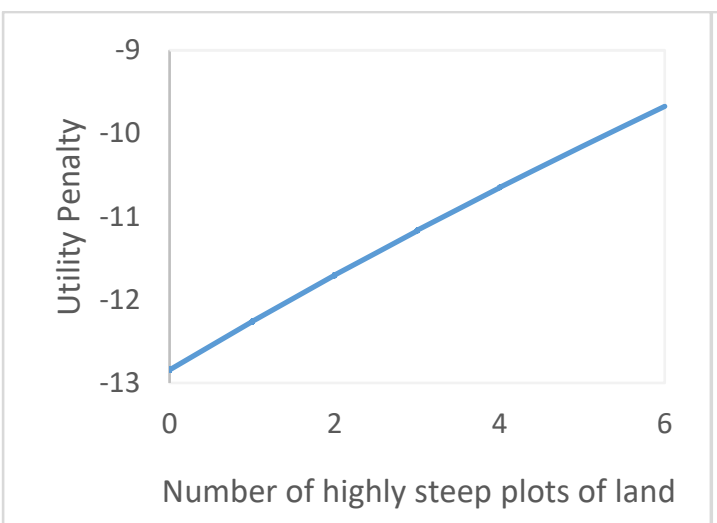

Panel III

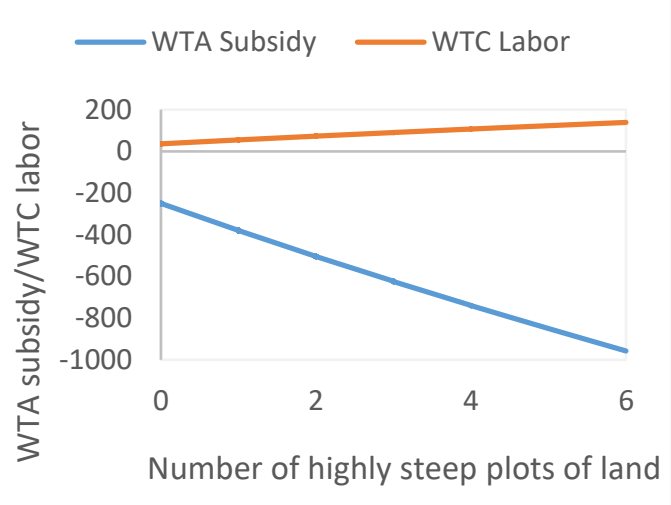

Panel IV

Figure 6. The effect of age on utility penalty and welfare holding other variables at their mean and dominant representative (group with highest share) for continuous and dummy variables respectively (Panel I and Panel II). Similarly, we apply the same rule to calculate utility penalty and welfare in response to the number of highly steep plots of land. 

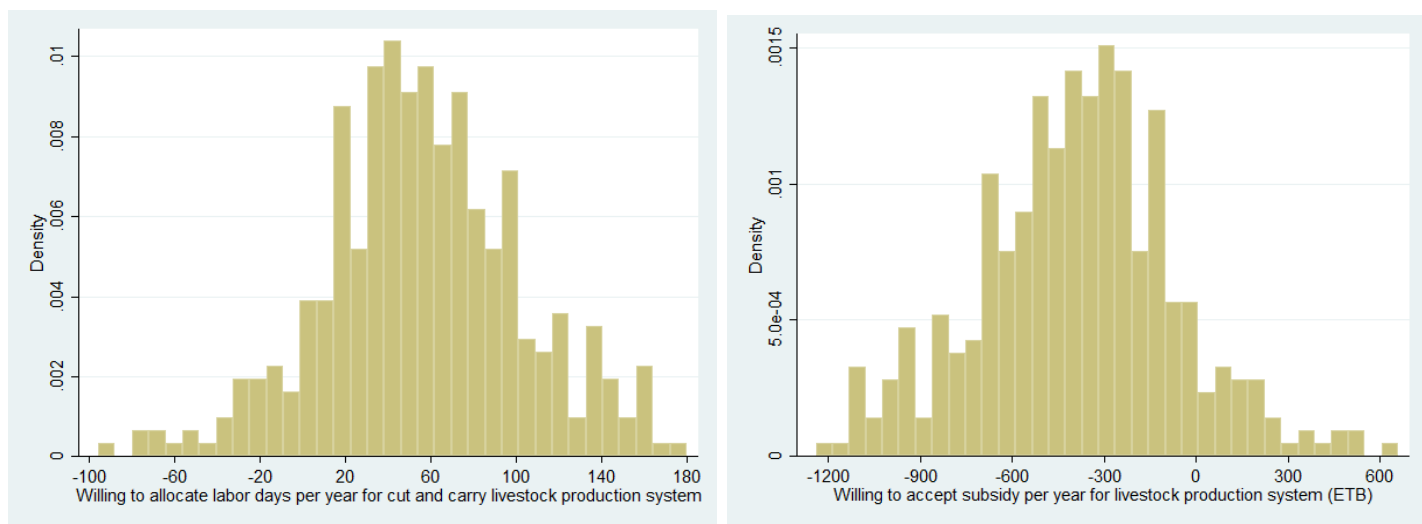

Figure 7. Willing to allocate labor days per year (left) and willingness to accept subsidy per year (right) for livestock production system

\section{Comparing welfare measures across models}

The welfare estimates for the two models (proposed SG-CSF and the base SG-MXL) are reported in Table 4. The standard deviations of the average welfare estimates are low for the proposed model (Panel A). We find a substantial difference in the average marginal welfare estimates for the "cut and carry" livestock management system across the two models, with the SG-MXL being $11 \%$ higher (more negative for WTA). For the other attributes the differences are insignificant . Comparing the estimates with results from Kassahun \& Jacobsen (2015) also show some difference in that the earlier study produces lower estimates ${ }^{15}$. This shows that accounting for heterogeneity originating from mutual expectations from cooperation and integrated land management matters for the estimates, but more importantly also for how to implement land-use policies.

So far, we have focused exclusively on parameters involved in the choice of livestock production system and the implied sensitivity of welfare estimates. We now turn our focus to

\footnotetext{
${ }^{15}$ Kassahun \& Jacobsen (2015) do not calculate sample average WTP, only WTP for each group. To compare their model with ours, we replicate their estimate and calculate average WTP. Statistically, the sample average value is lower for the "cut and carry" livestock management system in Kassahun \& Jacobsen (2015).
} 
the choice of on-farm conservation technologies. Of the three on-farm soil conservation technologies, we found preference heterogeneity on Soil Bund with Grass Strip (SBGS) and Stone Bund $(\mathrm{SB})^{16}$. These results are expected considering the wide variability in landscape, availability of stone for the construction of SB as well as the amount of labor required to implement these soil conservation technologies. We find no differences between the two models (Table 4).

Table 4: Willingness to contribute labor and willingness to accept subsidy to implement conservation contracts

Panel A: proposed model

Variable Mean Std. Dev. [95\% Conf. Interval]

Subsidy in Ethiopian Birr (ETB* per annum)

$\begin{array}{lllll}\text { Cut and carry livestock system } & -387.25 & 324.15 & -1022.59 & 248.09\end{array}$

$\begin{array}{lllll}\text { Soil bund with grass strip } & -177.70 & 7.81 & -193.01 & -162.40\end{array}$

$\begin{array}{lllll}\text { Stone bund } & -177.57 & 35.48 & -247.11 & -108.04\end{array}$

Labor contribution in days of labor per annum

$\begin{array}{lllll}\text { Cut and carry livestock system } & 56.18 & 47.03 & -35.99 & 148.36\end{array}$

$\begin{array}{lllll}\text { Soil bund with grass strip } & 25.78 & 1.13 & 23.56 & 28.00\end{array}$

$\begin{array}{lllll}\text { Stone bund } & 25.76 & 5.15 & 15.67 & 35.85\end{array}$

Panel B: SG-MXL model

\begin{tabular}{|c|c|c|c|c|}
\hline Variable & Mean & Std. Dev. & \multicolumn{2}{|c|}{ [95\% Conf. Interval] } \\
\hline \multicolumn{5}{|c|}{ Subsidy in Ethiopian Birr (ETB* per annum) } \\
\hline Cut and carry livestock system & -432.99 & 528.07 & -1468.01 & -602.03 \\
\hline Soil bund with grass strip & -173.51 & 9.63 & -192.39 & -154.63 \\
\hline Stone bund & -172.51 & 33.02 & -237.24 & -107.79 \\
\hline \multicolumn{5}{|c|}{ Labor contribution in days of labor per annum } \\
\hline Cut and carry livestock system & 66.77 & 81.44 & -92.84 & 226.39 \\
\hline Soil bund with grass strip & 26.76 & 1.48 & 23.85 & 29.67 \\
\hline Stone bund & 26.60 & 5.09 & 16.62 & 36.59 \\
\hline
\end{tabular}

${ }^{16}$ For all random parameters, we have assumed independent normal distributions. 
Two of the additional attributes of interest in this study are time preference for labor contribution and additional extension services. The mean and the standard deviation estimates of the parameters for the timing of labor contributions are significant (Table 3, Panel C). The relatively larger magnitude of the standard deviation shows a high degree of preference heterogeneity. We can conclude that on average farmers prefer labor contributions that are uniformly distributed across the year compared to the status quo. As expected, additional extension service is valued positively as implementation of different conservation technologies requires knowledge (Kassahun and Jacobsen 2015).

\section{Some caveats}

The current study applies a stated preference experiment implemented with a face-to-face interviewer method. It is natural to reflect on the potential for possible hypothetical or interviewer pleaser biases to influence the results, and in particular the aspects of signaling expectation towards and willingness to get involved in cooperation on new modes of common land management, which was in focus during the time the study was implemented. It is impossible to obtain a measure of such biases, if present, in a study like the present. However, given the fact that we find considerable variation in willingness to cooperate and are able to make sense of much of this variation, we speculate that any biases have not eroded the ability for us to obtain relevant insights into the focal issue.

We develop a measurement model including indicators of cooperation expectations to explain willingness to engage in land use systems that requires such cooperation. One may worry that respondents will signal to cooperate on the basis of other more general social preference aspects, sense of social norms or altruistic motivations. We note that we base this model on, among other things, questions specifically designed to have respondents relate to the possible presence or lack of mutual benefits from cooperation in common land management. Thus, 
whether the benefits include other benefit components (like utility gains from complying with social norms) or not, we find that it is justified to consider their responses to choice alternatives to embed the effects of cooperation.

Turning to our welfare estimates, we note that our welfare calculation is based on a subsidy on the interest rate (cancelling interest) corresponding to the rate of the commercial Bank of Ethiopia. This makes sense as the framing of the study is based on a contract between individual farmers and the government. However, care must be taken in dealing with interest rates for welfare calculation in the case of multiple credit providers with varied interest rates and different sets of collateral requirements to access credit services. In this situation, farmers may have individual-specific interest rates depending on their wealth or access to credit. If the interest rate is farmer-specific, the assumption of the same interest rate for all farmers leads to welfare estimates being biased.

Labor is an integral part of our conservation package and used as alternative instrument for welfare estimation. However, care must be taken when using a non-monetary unit such as labor for welfare estimation. This is because farmers may have different opportunity cost of labor time. Conversely, a significant proportion of farmers in developing countries do not supply labor to the market (Barrett et al. 2008). Thus, getting accurate value of labor opportunity cost for individual farmers requires a separate study. Nevertheless, the use of multiple payment vehicles is a way forward to get insight into the welfare implications of programs in developing countries (Kassahun and Jacobsen 2015, Schiappacasse et al. 2013).

\section{Conclusion}

In this article, we develop an econometric model of implicit choice set formation that accounts for farmers' expectations regarding mutual benefits from cooperation in a mixed land management system, and account for the potential interdependence of preferences across 
farmers in a social and spatial network. We show that both these effects are present and that omitting them may lead to wrong policy conclusions if relying on average estimates for livestock management system. The average welfare estimate for our model is $11 \%$ lower compared to the model that did not account for choice set formation arising from expectations about cooperation outcomes. Furthermore, the proposed model provides further insight by explaining the heterogeneity in the choice set.

To demonstrate our proposed method, we use data obtained from a discrete choice experiment (DCE) survey conducted among farmers in erosion hot-spots of the Ethiopian highlands in the Upper Blue Nile Basin (Kassahun and Jacobsen 2015). The motivation behind the survey was that soil erosion generated from cultivated and grazing land is causing serious on- and off-site damage across the Blue Nile River System, and there is a need to counter upstream farmers' currently low voluntary adoption rates of soil conservation technologies. The DCE survey was designed to address measures and incentives for common and private land management to reduce on-farm and off-farm impacts of soil erosion.

The choice set component of our model provides in depth information regarding cooperation expectation that helps effective policy implementation. We found that as farmers' expectations regarding positive cooperation outcomes increases so does their willingness to engage in systems requiring cooperation. The more difficult the farmer's land is to manage as measured by the number of highly steep plots of land owned by the farmer, the greater their willingness to cooperate. The willingness to contribute labor increases by $52 \%$ if the individual has a very steep plot of land compared to a person endowed with flat land. Farmers' expectations regarding positive cooperation decrease as the age of the farmer increases. Policy design targeting young farmers (age group 20 to30) leads to a substantial welfare gain (about 68\%) compared to targeting farmers between 50 and 60 . This effect consequently creates a 
substantial difference in the average marginal welfare estimate of "cut and carry" livestock management system on common lands compared to competing mis-specified models.

The model provides insights into how to increase the engagement of the region's farmers in the land management activity. Targeted additional extension services for the specific land management technology have a substantial effect on the engagement of economic agents in the conservation activity. Moreover, the engagement level of farmers can be substantially affected by the timing of labor contributions; equally distributed work commitments over the 12 months of the year is preferred compared to the current policy.

\section{Appendix A: Structural latent class model of Kassahun and Jacobson (2015)}

Kassahun and Jacobsen (2015) specified the structural latent class probability choice model with the product of the class membership probability and the conditional probability of choice.

$$
p_{n}=\sum_{s=1}^{s}\left[\frac{\exp \left(\theta_{s} Z_{n}\right)}{\sum_{s=1}^{s} \exp \left(\theta_{s} Z_{n}\right)}\right]\left[\frac{\exp \left(\beta_{s} X_{n i t}\right)}{\sum_{j=1}^{J_{i}} \exp \left(\beta_{s} X_{n j i}\right)}\right]
$$

where $\theta_{\theta}$ is the parameter estimate associated with the observed characteristics of individual $\mathrm{Zn}$. $\beta_{s}$ is the parameter vector associated with explanatory variables X. Furthermore, using the person-specific latent class probability (posterior estimates), Kassahun and Jacobsen (2015) calculate average socio-spatial group specific class probability. That result showed homogeneous preference across spatial units, which calls for further investigation for the potential screening processes of alternatives, and potential issues of endogeneity and spatial effect due to the interdependence of choices across the responding farmers sharing both spatial and social networks.

\section{Acknowledgments}


The data collection for this research was funded through the European Commission as part of the Erasmus Mundus Fellowship Program (Forest and Nature for Society, FONASO). However, the conceptualization of the paper and the method used in this manuscript were developed under postdoctoral support for H.T. Kassahun by Australian Research Council Discovery Project DP140103966 and the Centre for Macro-ecology, Evolution and Climate, the Danish National Research Foundation (grant number DNRF96).

\section{References}

Awulachew, S.B., M. McCartney, T. S. Steenhuis, and A. A. Ahmed (2008) A review of hydrology, sediment and water resource use in the Blue Nile Basin. IWMI Working Paper 131. Colombo, Sri Lanka: IWMI: 81p.

Banerjee, Simanti (2017) Improving Spatial Coordination Rates under the Agglomeration Bonus Scheme: A Laboratory Experiment with a Pecuniary and a Non-Pecuniary Mechanism (NUDGE). Am J Agr Econ:172-197.

Barrett, Christopher B., Shane M. Sherlund, and Akinwumi A. Adesina (2008) Shadow wages, allocative inefficiency, and labor supply in smallholder agriculture. Agr Econ 38 (1):21-34.

Bellemare, Marc F. (2009) When Perception is Reality: Subjective Expectations and Contracting. Am J Agr Econ 91 (5):1377-1381.

Ben-Akiva, Moshe , J. Walker, AT. Bernardino, DA Gopinath, T Morikawa, and A. Polydoropoulou (1999) Integration of choice and latent variable models. Massachusetts Institute of Technology. Cambridge, MA.

Ben-Akiva, Moshe, André Palma, Daniel McFadden, Maya Abou-Zeid, Pierre-André Chiappori, Matthieu Lapparent, Steven N. Durlauf, Mogens Fosgerau, Daisuke Fukuda, Stephane Hess, Charles Manski, Ariel Pakes, Nathalie Picard, and Joan Walker (2012) Process and context in choice models. Marketing Lett 23 (2):439-456. 
Bennett, J., and E. Birol, eds (2010) Choice experiments in developing countries : implementation, challenges and policy implications. Edward Elgar, Cheltenham.

Bhat, C. R. (2000) A multi-level cross-classified model for discrete response variables. Transportation Research Part B-Methodological 34 (7):567-582.

Bierlaire, Michel, and Mamy Fetiarison (2009) Estimation of discrete choice models: extending BIOGEME. Swiss Transport Research Conference (STRC).

Brady, Michael, and Elena Irwin (2011) Accounting for Spatial Effects in Economic Models of Land Use: Recent Developments and Challenges Ahead. Environ Resour Econ 48 (3):487-509.

Broch, Stine Wamberg, Niels Strange, Jette B. Jacobsen, and Kerrie A. Wilson (2013) Farmers' willingness to provide ecosystem services and effects of their spatial distribution. Ecol Econ $92(0): 78-86$.

Broch, StineWamberg, and SuzanneElizabeth Vedel (2012) Using Choice Experiments to Investigate the Policy Relevance of Heterogeneity in Farmer Agri-Environmental Contract Preferences. Environ Resour Econ 51 (4):561-581.

Brock, William A., and Steven N. Durlauf (2001) Discrete Choice with Social Interactions. The Review of Econ Studies 68 (2):235-260.

Cavalcanti, Carina, Stefanie Engel, and Andreas Leibbrandt (2013) Social integration, participation, and community resource management. J Environ Econ Manag 65 (2):262-276.

Christensen, Tove, Anders Branth Pedersen, Helle Oersted Nielsen, Morten Raun Mørkbak, Berit Hasler, and Sigrid Denver (2011) Determinants of farmers' willingness to participate in subsidy schemes for pesticide-free buffer zones-A choice experiment study. Ecol Econ 70 (8):15581564.

Cox, Michael, and Justin M. Ross (2011) Robustness and vulnerability of community irrigation systems: The case of the Taos valley acequias. J Environ Econ Manag 61 (3):254-266. 
Daly, Andrew, Stephane Hess, Bhanu Patruni, Dimitris Potoglou, and Charlene Rohr (2012) Using ordered attitudinal indicators in a latent variable choice model: a study of the impact of security on rail travel behaviour. Transportation 39 (2):267-297.

Delavande, A., X. Gine, and D. McKenzie (2011) Measuring subjective expectations in developing countries: A critical review and new evidence. J Dev Econ 94 (2):151-163.

Emmenegger, Rony, Sibilo Keno, and Tobias Hagmann (2011) Decentralization to the household: expansion and limits of state power in rural Oromiya. J Eastern African Studies 5 (4):733-754.

Eom, Young-Sook, and Douglas M. Larson (2006) Valuing housework time from willingness to spend time and money for environmental quality improvements. Review of Econ of the Household $4(3): 205-227$.

Epanchin-Niell, Rebecca S., and James E. Wilen (2015) Individual and Cooperative Management of Invasive Species in Human-mediated Landscapes. Am J Agr Econ 97 (1):180-198.

Gibson, J. M., D. Rigby, D. A. Polya, and N. Russell (2016) Discrete Choice Experiments in Developing Countries: Willingness to Pay Versus Willingness to Work. Environ Resour Econ 65 (4):697721.

Greiner, Romy, Michiel Bliemer, and Julie Ballweg (2014) Design considerations of a choice experiment to estimate likely participation by north Australian pastoralists in contractual biodiversity conservation. J Choice Modelling 10:34-45.

Hess, S., and N. Beharry-Borg (2012) Accounting for Latent Attitudes in Willingness-to-Pay Studies: The Case of Coastal Water Quality Improvements in Tobago. Environ Resour Econ 52 (1):109-131. Hess, Stephane, Kenneth E. Train, and John W. Polak (2006) On the use of a Modified Latin Hypercube Sampling (MLHS) method in the estimation of a Mixed Logit Model for vehicle choice. Transportation Research Part B: Methodological 40 (2):147-163.

Hurd, Michael D. (2009) Subjective Probabilities in Household Surveys. Annual Review of Econ 1:543562. 
Kaczan, David, Brent M. Swallow, and W. L. Adamowicz (2013) Designing a payments for ecosystem services (PES) program to reduce deforestation in Tanzania: An assessment of payment approaches. Ecol Econ 95:20-30.

Karlan, Dean, Markus Mobius, Tanya Rosenblat, and Adam Szeidl (2009) Trust and Social Collateral. Q J Econ 124 (3):1307-1361.

Kassahun, Habtamu Tilahun (2014) Advances in stated preference studies for valuing and managing the environment, a developing country context. PhD Thesis, University of Copenhagen.

Kassahun, Habtamu Tilahun, and Jette Bredahl Jacobsen (2015) Economic and institutional incentives for managing the Ethiopian highlands of the Upper Blue Nile Basin: A latent class analysis. Land Use Policy 44 (0):76-89.

Kassahun, Habtamu Tilahun, Charles F. Nicholson, Jette Bredahl Jacobsen, and Tammo S. Steenhuis (2016) Accounting for user expectations in the valuation of reliable irrigation water access in the Ethiopian highlands. Agr Water Manag 168:45-55.

Klaiber, H. Allen , and Daniel J. Phaneuf (2010) Valuing open space in a residential sorting model of the Twin Cities. J Environ Econ Manag 60 (2):57-77.

Krishna, V. V., A. G. Drucker, U. Pascual, P. T. Raghu, and Edio King (2013) Estimating compensation payments for on-farm conservation of agricultural biodiversity in developing countries. Ecol Econ 87:110-123.

Li, Lianhua, Wiktor Adamowicz, and Joffre Swait (2015) The effect of choice set misspecification on welfare measures in random utility models. Resour Energy Econ 42:71-92.

Lienhoop, Nele, and Roy Brouwer (2015) Agri-environmental policy valuation: Farmers' contract design preferences for afforestation schemes. Land Use Policy 42:568-577.

Manski, Cf (1993a) Identification problems in the social-sciences. Sociological Methodology 23:1-56.

Manski, Charles F. (1993b) Identification of Endogenous Social Effects: The Reflection Problem. The Review of Economic Studies 60 (3):531-542.

Manski, Charles F. (2004) Measuring Expectations. Econometrica 72 (5):1329-1376. 
Manski, CharlesF (1977) The structure of random utility models. Theory Dec 8 (3):229-254.

Martínez, Francisco, Felipe Aguila, and Ricardo Hurtubia (2009) The constrained multinomial logit: A semi-compensatory choice model. Transportation Research Part B: Methodological 43 (3):365-377.

McFadden, D. (2010) Sociality, Rationality, and the Ecology of Choice. In Hess, S. and Daly, A. (Ed.) Choice Modelling: The State-of-the-art and The State-of-practice. Emerald Group Publishing Limited, UK.

McFadden, Daniel, and Kenneth Train (2000) Mixed MNL Models for Discrete Response. J Applied Econometrics 15 (5):447-470.

Neilson, William, and Bruno Wichmann (2014) Social networks and non-market valuations. J Environ Econo Manag 67 (2):155-170.

Oh, H., and J. H. Hong (2012) Citizens' trust in government and their willingness-to-pay. Econ Lett 115 (3):345-347.

Ostrom, E., J. Burger, C. B. Field, R. B. Norgaard, and D. Policansky (1999) Revisiting the commons: Local lessons, global challenges. Science 284 (5412):278-282.

Ostrom, Elinor (1990) Governing the Commons, The Evolution of Institutions for Collective Action. Cambridge University Press, Cambridge.

Ostrom, Elinor (2000) Collective Action and the Evolution of Social Norms. J Economic Perspectives 14 (3):137-158.

Ostrom, Elinor, and Michael Cox (2010) Moving beyond panaceas: a multi-tiered diagnostic approach for social-ecological analysis. Environmental Conservation 37 (04):451-463.

Pelosi, C., M. Goulard, and G. Balent (2010) The spatial scale mismatch between ecological processes and agricultural management: Do difficulties come from underlying theoretical frameworks? Agriculture Ecosystems \& Environment 139 (4):455-462. 
Pimentel, David (2006) Soil erosion: A food and environmental threat. Environment Development and Sustainability 8 (1):119-137.

Pimentel, David, Celia Harvey, Pradnja Resosudarmo, K Sinclair, D Kurz, M McNair, S Crist, L Shpritz, L Fitton, and Ri Saffouri (1995) Environmental and economic costs of soil erosion and conservation benefits. Science-AAAS-Weekly Paper Edition 267 (5201):1117-1122.

Rai, Rajesh Kumar, and Helen Scarborough (2013) Economic value of mitigation of plant invaders in a subsistence economy: incorporating labour as a mode of payment. Environ Dev Econ 18:225244.

Richards, Timothy J., Stephen F. Hamilton, and William J. Allender (2014) Social Networks and New Product Choice. Am J Agr Econ 96 (2):489-516.

Rustagi, Devesh, Stefanie Engel, and Michael Kosfeld (2010) Conditional Cooperation and Costly Monitoring Explain Success in Forest Commons Management. Science 330 (6006):961-965.

Schiappacasse, I., F. Vasquez, L. Nahuelhual, and C. Echeverria (2013) Labor as a welfare measure in contingent valuation: the value of a forest restoration project. Ciencia E Investigacion Agraria $40(1): 69-84$.

Sidharthan, R., and C. R. Bhat (2012) Incorporating Spatial Dynamics and Temporal Dependency in Land Use Change Models. Geographical Analysis 44 (4):321-349.

Swait, Joffre, and Vic Adamowicz (2014) Choosing how best to choose: Antecedent Volition and decision process representation in discrete choice models. J Choice Modelling 13 (0):1-2.

Swait, Joffre, and Moshe Ben-Akiva (1987) Incorporating random constraints in discrete models of choice set generation. Transportation Research Part B: Methodological 21 (2):91-102.

Swait, Joffre, Neil Brigden, and Richard D. Johnson (2014) Categories shape preferences: A model of taste heterogeneity arising from categorization of alternatives. J Choice Modelling 13 (0):323.

Swait, Joffre Dan. 1984. Probabilistic choice set generation in transportation demand models, Dept. of Civil Engineering, Massachusetts Institute of Technology. 
Swait, Joffre, and Jordan Louviere (1993) The Role of the Scale Parameter in the Estimation and Comparison of Multinomial Logit Models. J Marketing Res 30 (3):303-314.

Swait, Joffre, Jordan J. Louviere, and Michael Williams (1994) A sequential approach to exploiting the combined strengths of SP and RP data: Application to freight shipper choice. Transportation $21(2): 135-152$.

Teferi, E., S. Uhlenbrook, W. Bewket, J. Wenninger, and B. Simane (2010) The use of remote sensing to quantify wetland loss in the Choke Mountain range, Upper Blue Nile basin, Ethiopia. Hydrology and Earth System Sciences 14 (12):2415-2428.

Tesfaye, A., and R. Brouwer (2012) Testing participation constraints in contract design for sustainable soil conservation in Ethiopia. Ecol Econ 73:168-178.

Thiene, Mara, Joffre Swait, and Riccardo Scarpa (2017) Choice set formation for outdoor destinations: The role of motivations and preference discrimination in site selection for the management of public expenditures on protected areas. J Environ Econ Manag 81:152-173.

Tobler, Waldo R. (1979) Smooth Pycnophylactic Interpolation for Geographical Regions. J Am Statistical Assoc 74 (367):519-530.

Trawick, PaulB (2001) Successfully Governing the Commons: Principles of Social Organization in an Andean Irrigation System. Human Ecology 29 (1):1-25.

Vedel, Suzanne Elizabeth, Jette Bredahl Jacobsen, and Bo Jellesmark Thorsen (2015) Contracts for afforestation and the role of monitoring for landowners' willingness to accept. Forest Policy Econ 51:29-37.

Videras, Julio, Ann L. Owen, Emily Conover, and Stephen Wu (2012) The influence of social relationships on pro-environment behaviors. J Envir Econ Manag 63 (1):35-50.

Vij, A., and J. Walker (2014) Hybrid choice models: The identification problem. In Hess, S. and Daly, A. (Ed.) Handbook of Choice Modelling. Edward Elgar, UK.

Vollan, Björn, and Elinor Ostrom (2010) Cooperation and the Commons. Science 330 (6006):923-924. 
Walker, Joan L., Emily Ehlers, Ipsita Banerjee, and Elenna R. Dugundji (2011) Correcting for endogeneity in behavioral choice models with social influence variables. Transportation Research Part A: Policy and Practice 45 (4):362-374.

Wang, Yang (2014) Dynamic Implications of Subjective Expectations: Evidence from Adult Smokers. American Economic Journal: Applied Econ 6 (1):1-37. 